\title{
Deflation Probability and the Scope for Monetary Loosening in the United Kingdom*
}

\author{
Alex Haberis, ${ }^{\mathrm{a}, \mathrm{b}}$ Riccardo M. Masolo, ${ }^{\mathrm{a}, \mathrm{b}}$ and Kate Reinold ${ }^{\mathrm{a}}$ \\ ${ }^{a}$ Bank of England \\ ${ }^{\mathrm{b}}$ Centre for Macroeconomics, London
}

\begin{abstract}
We use an estimated DSGE model of the U.K. economy to investigate perceptions of the scope for monetary loosening since the 2007-08 financial crisis. We simulate our model under alternative assumptions about the constraints on monetary policy and compare the implied deflation probabilities with those expected by professional forecasters, financial markets (from options prices), and policymakers. We find that these real-time, external estimates of deflation probability are consistent with policy not having been perceived to have been constrained since the crisis.
\end{abstract}

JEL Codes: E31, E37, E43, E47, E52.

\section{Introduction}

In the aftermath of the 2007 to 2008 financial crisis, the U.K. economy fell into its deepest recession for decades, experiencing a peakto-trough fall in GDP larger than either the United States or the euro area 1 There was also substantial volatility in inflation, in part

\footnotetext{
*Copyright (C) 2019 Bank of England. Any views expressed are solely those of the authors and so cannot be taken to represent those of the Bank of England or to state Bank of England policy. This paper should therefore not be reported as representing the views of the Bank of England, the MPC, the FPC, or the PRC. The authors would like to thank the co-editor Boragan Aruoba, three anonymous referees, Günter Coenen, Paolo Surico, Garry Young, and participants at the 2016 SNDE Conference at the University of Alabama and the $2016 \mathrm{MMF}$ Conference at the University of Bath for useful comments and discussions. The authors would also like to thank Will Dison and Ali Schomberg for their help in compiling the option-based estimates.

${ }^{1}$ The peak-to-trough fall in output in the United Kingdom during the Great Recession was 6.1 percent, compared with 4.2 percent in the United States and 5.8 percent in the euro area.
} 
due to fluctuations in the exchange rate: the high degree of openness of the U.K. economy can make inflation more difficult to control in the face of these international factors than in less open economies, such as the United States and the euro area 2 As the effects of the exchange rate fluctuations waned, inflation quickly fell below the Bank of England's Monetary Policy Committee's (MPC) 2 percent target, and there were concerns that it could fall further. In response to the weakening economic and inflation outlook, the MPC cut the policy rate (Bank Rate) to historically low levels and conducted a wide range of unconventional policy measures, including quantitative easing (QE) 3 There was uncertainty, however, about the marginal effectiveness of cuts in policy rates to such low levels. Moreover, to the extent that the unconventional measures had not been used before in the United Kingdom, it was unclear what their effects would be - e.g., in its 2009 Article IV Staff Report, the International Monetary Fund stated that it was "too early to judge the effectiveness of QE" (IMF 2009, p. 35). Therefore, the combination of (i) an unusually deep recession by international standards, (ii) high volatility in inflation on account of the United Kingdom's openness, and (iii) a wide range of hitherto untested policy measures raises the question of whether monetary policy was perceived to have been constrained in its ability to counteract deflationary shocks since the onset of the financial crisis in the United Kingdom.

In this paper we infer perceptions about the scope for monetary loosening in the United Kingdom over this period by comparing the estimates of the probability of deflation of professional forecasters, financial markets, and policymakers to model-based estimates produced under alternative assumptions about the effectiveness of

\footnotetext{
${ }^{2}$ In small open-economy models (e.g., Galí and Monacelli 2005; De Paoli 2009), it can be shown that the more open the economy, the less responsive is domestic inflation to the domestic output gap. In addition, foreign variables and international relative prices themselves can be a source of volatility in inflation in these models. While it is possible for fluctuations in international variables, such as the exchange rate, not to pose a tradeoff for domestic monetary policy between stabilizing inflation and the output gap, this requires quite restrictive assumptions (e.g., Clarida, Galí, and Gertler 2002; Galí and Monacelli 2005). More generally, it will not be possible for home monetary policy to stabilize domestic inflation without sacrificing other policy goals (e.g., De Paoli 2009; Corsetti, Dedola, and Leduc 2010).
}

${ }^{3}$ To be outlined in section 2 . 
policy 4 It is necessary to infer perceptions since, by their nature, they are not observable. Deflation probabilities are a good lens through which to consider this issue since, if monetary policy were perceived to have been constrained, we would expect to see material downside risks in forecasts for inflation 5 A wide range of estimates of deflation probability are available for the United Kingdom, including those derived from the MPC's own forecasts, from financial markets (from option prices), and from professional forecasters (Survey of External Forecasters). By considering perceptions of monetary policy constraints in the post-crisis period, our paper is related to Swanson and Williams (2013, 2014).

To construct our model-based estimates of deflation probability, we use stochastic simulations of a real-time estimated DSGE model of the U.K. economy to produce forecast densities for inflation for each quarter between 2007:Q1 and 2016:Q2. To add greater realism to our simulations, we base them around the MPC's forecasts as published in the Inflation Report (IR). We implement the simulations under two alternative assumptions about monetary policy. At one end of the spectrum, policy is entirely unconstrained in its response to disinflationary shocks. At the other, we assume that policy rates face an effective lower bound (ELB) of 0.5 percent (the floor for Bank Rate over our sample) that limits the policymaker's ability to counteract shocks 6 We interpret the former case as being consistent with monetary policy (including unconventional measures) being effective; the latter case is consistent with monetary loosening being ineffective or infeasible. By exploring inflation risks through the stochastic simulation of a DSGE model with an ELB on policy rates, our work closely relates to that of Coenen and Warne (2014) and also to the assessment of Chung et al. (2012) of the likelihood of zero-lower-bound events.

\footnotetext{
${ }^{4}$ We define a deflationary episode as any quarter in which the annual inflation rate is negative.

${ }^{5}$ In New Keynesian models, if the effectiveness of monetary policy is constrained by the effective lower bound in response to a disinflationary shock, inflation would be materially weaker than if policy were unconstrained. For example, see Eggertsson and Woodford (2003).

${ }^{6}$ We impose the ELB using the shadow-price shock approach of Holden and Paetz (2012). This implementation has parallels with that outlined in Guerrieri and Iacoviello (2015).
} 
We find that the external deflation-probability estimates are consistent with the perception that monetary policy had scope to loosen in response to disinflationary shocks in the period since 2007. In our external estimates, the probability of deflation is heightened in 2009 and in 2015 - a pattern that is broadly matched in our model simulations in the absence of a constraint on policy. That the simulated and external estimates are close suggests that our model can accurately capture the perceived risk of deflation. By contrast, in our simulations produced under the assumption of a constraint on policy, there is also an episode of increased probability of deflation in late 2011 to 2013, in addition to the 2009 and 2015 episodes, which we can use to "identify" agents' perceptions about the effectiveness of monetary policy. This episode is special because the heightened deflation probability is entirely driven by the expected lack of scope for monetary policy to loosen; when we do not impose a floor on the level of the policy rate, the risk of deflation recedes.

The rest of the paper proceeds as follows. Section 2 discusses monetary policy and economic developments in the United Kingdom since 2007; section 3 presents the external estimates of deflation probability; section 4 outlines our model and the methodology for the stochastic simulations, including the imposition of the ELB; section 5 describes our results; and section 6 concludes.

\section{U.K. Monetary Policy and Economic Developments since 2007}

We begin by describing the main phases of the exceptional monetary policy measures conducted between 2007 and mid-2016, as well as the economic backdrop against which they were implemented. By setting out the raft of measures that were adopted, we hope to provide context for why the effectiveness of monetary policy might have been in question over this period. Moreover, we describe the evolution of the inflation outlook, which turns out to be key for distinguishing between the episodes of heightened deflation probability identified by our simulations.

\subsection{Financial Crisis and Great Recession, 2007 to 2009}

The financial crisis led to a substantial decline in real GDP (over 6 percent from early 2008 to mid-2009). In addition, although there 


\section{Figure 1. Annual CPI Inflation and Annual Real GDP Growth}

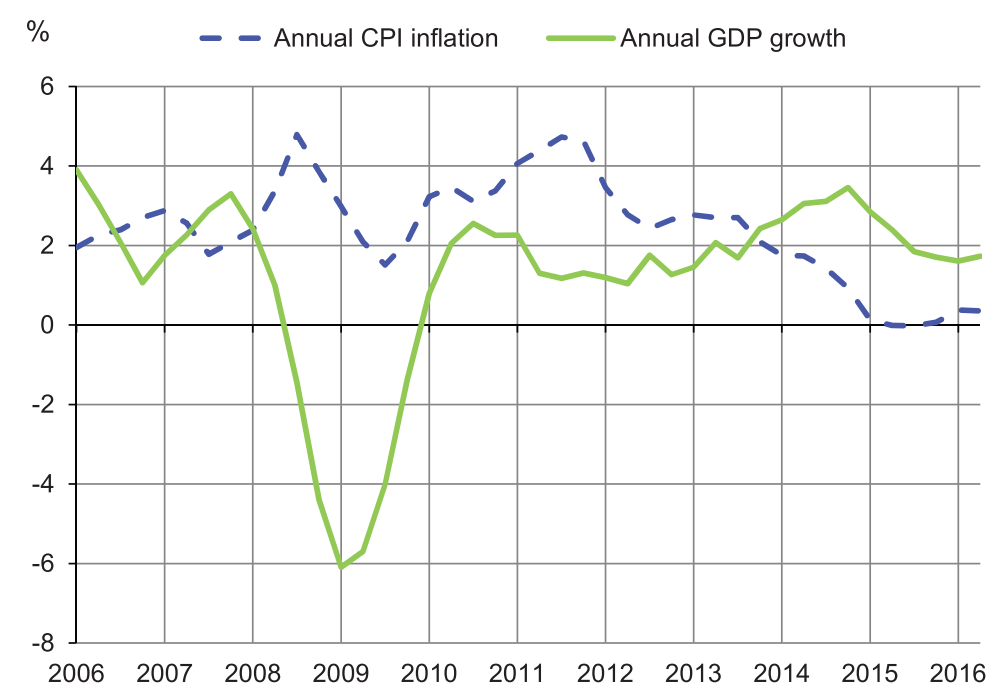

was a sharp increase in inflation, to around 5 percent in September 2008, it rapidly fell back, to around 1.5 percent a year later (figure 1 ), and there were concerns that it could fall further. This inflation volatility reflected the combined effects of a 20 percent depreciation of sterling (a key driver for U.K. inflation given its high degree of openness), one-off factors (such as a 2.5 percentage point reduction in value-added tax, VAT), and the material downturn in real activity.

The MPC initially responded to these exceptional conditions by cutting Bank Rate from 5 percent in September 2008 to a historic low of 0.5 percent by March 2009, a level considered to be its ELB at the time 7 In addition, the MPC judged that further monetary loosening would be required, and in March 2009 announced a large

\footnotetext{
${ }^{7}$ In particular, the February 2009 MPC minutes discussed the possibility that the impairment of the banking sector would limit pass-through of further Bank Rate cuts to deposit rates, so limiting the effect on real activity (MPC 2009). In February 2015 the MPC announced that cuts in Bank Rate towards zero from 0.5 percent were feasible on account of the improved capitalization of the U.K. banking system (MPC 2015, p. 8). That said, it left Bank Rate at 0.5 percent until August 2016, when it was cut to 0.25 percent (when it was also restated that further cuts towards zero were possible).
} 
program of $\mathrm{QE} 8$ Nevertheless, there remained concern that these measures would be insufficient. The impairment of the transmission mechanism due to the crisis meant that there was uncertainty around how stimulative the cuts in policy rates towards the ELB would be. Moreover, the MPC reported that it was mindful that "the impact of [asset purchases] was both uncertain and subject to time lags" (MPC 2009, p. 9). External commentary also highlighted the importance of these monetary measures if the United Kingdom was to avoid deflation. The Economist suggested that QE was "designed to combat deflation, the new bogeyman" (Economist 2009). The IMF stated that a "slip into outright deflation is unlikely but cannot be ruled out ... it is yet too early to judge the effectiveness of QE" (IMF 2009, pp. 33, 35).

\subsection{Spillover Effects from Euro-Area Crisis, Late 2011 to 2013}

Despite having seen some recovery in GDP growth and inflation over 2010 and early 2011, the MPC embarked upon further asset purchases in late 2011, of $£ 75$ billion, citing the "scale of the downward reassessment of the medium-term inflation outlook" (MPC 2011, p. 9). This was the MPC's first new round of QE since 2009, and it came despite an inflation rate at the time of around 5 percent. Policymakers attributed this high inflation to the effects of idiosyncratic factors such as an increase in VAT and student tuition fees, as well as the lagged impact of increased import and energy prices. With these effects in the past, however, slack in the labor market and a weak outlook for demand-reflecting in large part the euroarea crisis - were expected to put downward pressure on inflation. Figure 1 shows that inflation did fall sharply during 2012 and GDP growth softened further. This weakness in the outlook was also discussed by the IMF: "inflation is now falling [and] further disinflation is expected" and "anemic wage growth and well-contained inflation

\footnotetext{
${ }^{8}$ In addition to these monetary policy measures, the Bank of England had in April 2008 already set up the Special Liquidity Scheme to support the liquidity position of the banking system, a side effect of which would have been to improve the functioning of the monetary transmission mechanism at a time when it had been disrupted by the financial crisis. See John, Roberts, and Weeken (2012) for more details.
} 
expectations provide scope for further monetary stimulus to close the output gap faster and avoid inflation undershooting in the medium term" (IMF 2012, pp. 25, 31).

In light of these uncertain prospects, this period saw further policy innovations. In July 2012, the Bank of England and HM Treasury launched the Funding for Lending Scheme (FLS), designed to boost bank lending to households and firms 9 Furthermore, with a continued weak inflation outlook, in August 2013 the MPC introduced a policy of "threshold-based forward guidance" (focused on unemployment), designed to make existing monetary stimulus more effective 10

\subsection{Persistently Below-Target Inflation, 2014 to 2016}

As risks to the euro area dissipated, GDP growth in the United Kingdom strengthened throughout 2014 and inflation returned to target (figure 1). However, the MPC still saw material spare capacity in the economy and in February 2014 issued further guidance to assure the private sector that monetary tightening was not imminent 11

Inflation continued to fall and, over 2015, averaged just 0 percent (and on the monthly measure, deflation was actually recorded) 12 This represented another episode in which the United Kingdom's high degree of openness affected the ability of monetary policy to keep inflation at target: the MPC attributed weakness in inflation

\footnotetext{
${ }^{9}$ In particular, it aimed to reduce bank funding costs, which had increased on account of the intensification of the euro-area crisis. See Churm and Radia (2012) for more details.

${ }^{10}$ The guidance made clear that Bank Rate would not be raised from 0.5 percent, nor would stocks of purchased assets be run down, until the unemployment rate had fallen below 7 percent, subject to "knockouts" on the inflation outlook, inflation expectations, and financial stability (MPC 2013). The MPC also stated that it could further increase QE if necessary.

${ }^{11}$ The guidance stated that there remained spare capacity to justify the continued low level of Bank Rate even after the threshold had been crossed; that the pace of Bank Rate rises, when they occurred, would be "gradual"; and that in the medium term the level of Bank Rate would be "materially below the $5 \%$ level set on average by the Committee prior to the financial crisis" (MPC 2014, p. 10).

${ }^{12}$ Note that no deflation was recorded at the quarterly frequency, and hence is not apparent in figure 1. This figure and the analysis in section 5 focus on inflation at the quarterly frequency, given our use of quarterly deflation estimates in section 3 and a quarterly model, as discussed in section 4 .
} 
to the combined effects of an appreciation of sterling, as well as a drop in oil prices. Despite the seemingly temporary nature of this inflation weakness, the monthly deflation episode garnered wide press coverage 13 While much of the coverage accepted the MPC's account, some worries emerged. For example, an article in the Financial Times suggested that "the effect deflation would have on real debt burdens [was a] more serious reason for concern" (Coyle 2015). Moreover, in its assessment of the U.K. economy in 2015, the IMF highlighted the risks to inflation associated with possible limits on monetary policy: "[the] risks of policy errors are asymmetric - when the policy rate is close to its lower bound, the costs of inflation undershooting exceed those of overshooting" (IMF 2016, p. 23).

\section{External Estimates of the Probability of Deflation}

We consider ex ante estimates of deflation probability derived from three sources: first, the MPC's forecasts; second, inflation options prices; and third, a sample of professional forecasters. These represent alternative estimates of deflation risk as perceived in real time over the period.

(i) Policymakers: The MPC produces projections for annual CPI inflation (as well as GDP) in the form of interval forecasts - widely known as "fan charts." The fan charts look ahead over the next thirteen quarters and are published on a quarterly basis (in February, May, August, and November) in the IR. Although the MPC uses a central model in its forecast process, the projections are ultimately judgmental 14 Specifically, they are produced by translating MPC judgment into the parameters of a two-part normal distribution for each quarter of the forecast and are published in terms of particular probability intervals. To compute deflation probabilities, therefore, we use the two-part normal distribution and the MPC's published moments and calculate the probability of inflation falling below zero at each point over the

\footnotetext{
${ }^{13}$ For example, among others, British Broadcasting Corporation (2015), Khan (2015), and Kollewe (2015).

${ }^{14}$ See Burgess et al. (2013) for details on the forecast process and model.
} 
forecast horizon 15 We do this for each forecast vintage to build up a time series. Finally, the fan charts we use here are based on a conditioning assumption that Bank Rate follows the path expected by financial markets 16

(ii) Financial Markets: It is possible to calculate probability density functions (PDFs) for inflation - and hence deflation probabilities - from the prices of inflation options 17 The PDFs are produced on a daily basis. Two important assumptions underpin the calculations. First, the probability of deflation implied by these options is only equivalent to investors' true assessment of the probability of deflation under the assumption that options prices do not build in a risk premium. Were investors actually to be risk averse, and were the dislike of deflation to rise, it would look like a rise in the probability of deflation. Second, an adjustment has been made to reflect the fact that the options are traded on the retail price index (rather than the consumer price index on which our simulations are based) 18

(iii) Professional Forecasters: Each quarter the Bank of England conducts the Survey of External Forecasters (SEF), which asks a sample of private-sector forecasters for their latest economic projections, including for CPI inflation. Respondents

\footnotetext{
${ }^{15}$ The width of the fan chart is scaled judgmentally, informed by past forecast errors. The MPC incorporates skews into the distributions if it believes that the risks to the outlook are weighted in one direction. In addition, the MPC's fan charts only represent 90 percent of the distribution. The area outside the fans is not necessarily assumed to follow the two-part normal in the MPC's projections. However, for our purposes, we are assuming that the remaining 10 percent is distributed in the same way as the central 90 percent. See the box on pages $48-49$ of the May 2002 IR (MPC 2002) for a fuller description of the MPC's fan charts.

${ }^{16}$ Financial markets' expectations for Bank Rate are computed as a fifteen-day average in the period preceding the IR's publication.

${ }^{17}$ These are financial instruments that allow investors to take a position on caps and floors of future inflation outturns. For more information, see Smith (2012).

${ }^{18}$ These indexes differ according to the statistical approach used to aggregate prices and their coverage. On average, RPI inflation is around 1 percentage point higher than the CPI index and so we compute the deflation probability as RPI inflation of less than 1 percent. As a result, we correct the data by that amount, at the risk of missing potential changes in the wedge or in the markets' expectations of the wedge over time.
} 
are asked to assign probabilities for annual CPI inflation lying in particular buckets at one, two, and three years ahead. Since 2009 the survey has included a category for "less than $0 \%$ " which maps neatly into our analysis. The responses are presented as mean values across respondents.

Since 2007 there have been two episodes in which the probability of deflation on these estimates has been heightened. This can be seen in figure 2, which plots the probability of deflation one, two, and three years ahead (where the MPC and option-implied estimates are shown on the LHS vertical axis, and the SEF on the RHS). The three estimates show a high degree of co-movement, and the probability of deflation for each estimate spikes around 2009 and from around 2015 19 The spikes are most pronounced in the one-yearahead forecasts for the different estimates. The 2009 episode is the most persistent, with the probability of deflation elevated in each year of the forecasts, consistent with the IMF's concerns at the time. The 2015 episode, by contrast, has high probabilities of deflation initially, which are almost comparable to those in 2009. For the second and third years of the forecasts, however, the probability of deflation drops away more quickly. Despite the public discussion of the risks to the economy and the possible need for more unconventional policy interventions, these external estimates of deflation probabilities were relatively low at all horizons in the late-2011 to 2013 period.

\section{Methodology}

To infer the perceptions about the effectiveness of monetary policy as embodied in the external deflation-probability estimates in section 3 , we conduct simulations of an estimated DSGE model of the U.K. economy under alternative assumptions about the ability of policy to loosen to counteract disinflationary shocks. From the simulations we can construct model-implied probabilities of deflation, which we can compare with those of the three groups of agents we present

\footnotetext{
${ }^{19}$ The level of the SEF estimate is noticeably lower, possibly consistent with SEF participants' central projection for inflation displaying a positive bias, as discussed by Boero, Smith, and Wallis (2008). However, for our exercise, it is the change in the deflation probability over time that is important.
} 


\section{Figure 2. External Estimates of Deflation Probability}
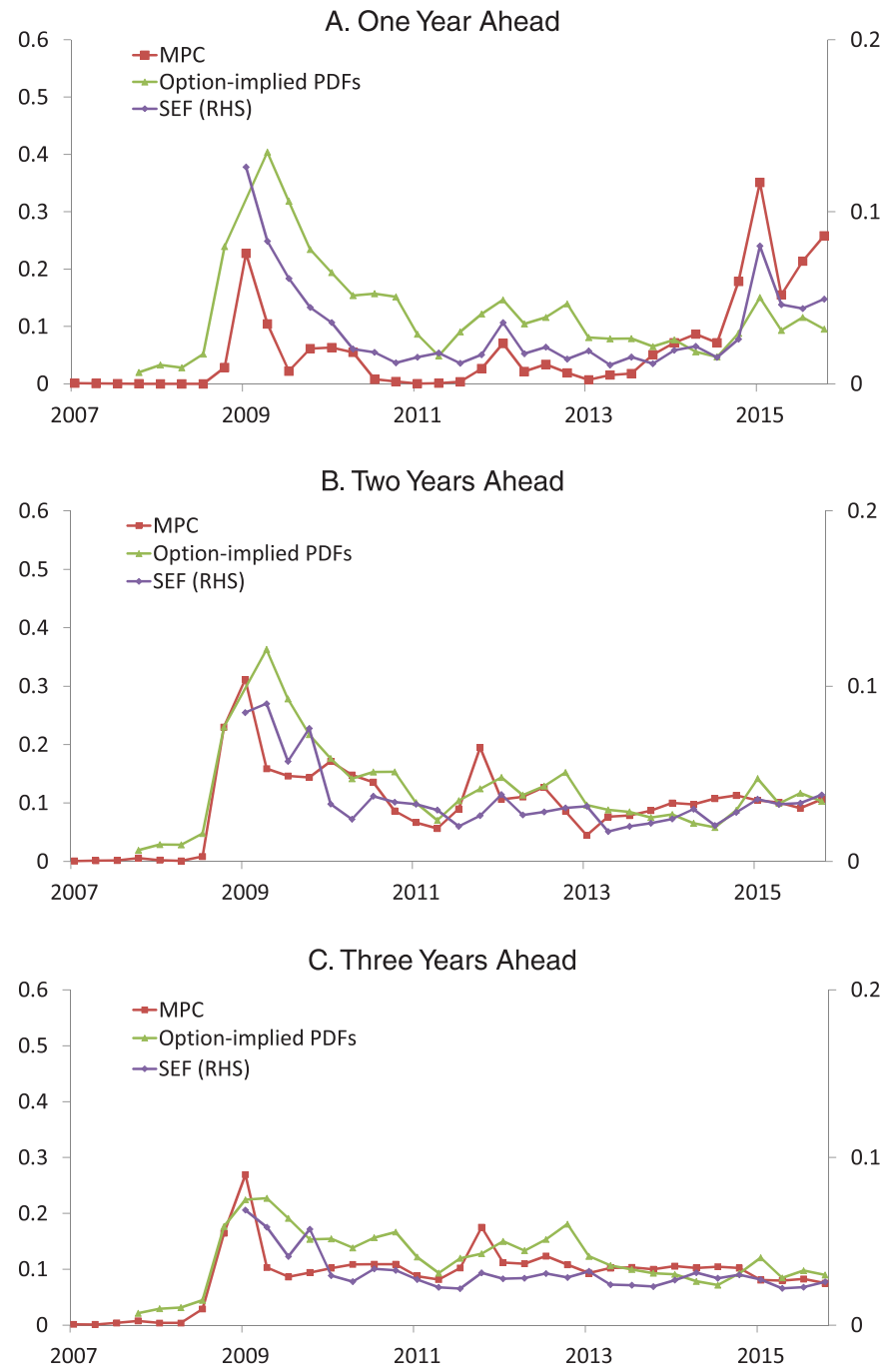

Notes: MPC indicates the probability of deflation from the published Inflation Report fan charts. Option-implied PDF estimates are computed as the probability of RPI inflation below 1 percent (equivalent to deflation in CPI given an average 1 percentage point wedge), as implied by the inflation distribution imputed from options prices. These are available daily (apart from some missing data) but have been converted into quarterly averages to be consistent with the other estimates of deflation probability. The SEF reports the probability that respondents to the Bank of England's Survey of Economic Forecasters assigned to CPI inflation falling below 0 percent one, two, and three years ahead (available from 2009). The MPC and option-implied estimates are shown on the LHS vertical axis, and the SEF on the RHS. 
above. Here, we describe the model, the estimation procedure, and the stochastic-simulation routine that we adopt.

\subsection{Model}

Our model is a medium-sized DSGE model in the tradition of Christiano, Eichenbaum, and Evans (2005) and Smets and Wouters (2007), augmented with a stylized description of the world economy 20 It is closely related to Burgess et al. (2013) and bears many similarities to other models used in central banks around the world, such as Christoffel, Coenen, and Warne (2008), Adolfson et al. (2013), and Dorich et al. (2013).

Households in the model consume final goods and supply labor to firms. There are two types of household: optimizers are forward looking and their consumption and saving decisions are the result of an intertemporal optimization problem. They set their wages in a monopolistically competitive labor market à la Erceg, Henderson, and Levin (2000). Hand-to-mouth households, by contrast, consume their labor income on a period-by-period basis, and take the wage rate as given. Optimizing households' savings are managed by portfolio packagers who can invest in domestic and foreign non-statecontingent bonds, which gives rise to an uncovered interest parity (UIP) condition.

The production side of the economy features monopolistically competitive sectors for value-added, final-output, imported, and exported goods, as well as competitive sectors that transform final output into consumption, private and government, and investment 21 Monopolistically competitive firms face pricing frictions à la Calvo (1983). However, when an opportunity to reset their prices arises, not all firms in these sectors behave optimally. In light of survey evidence (e.g., see Greenslade and Parker 2012), we assume that a share of firms follows simple rules of thumb that are only optimal on average (i.e., in steady state), in the same vein as Galí and Gertler (1999), Steinsson (2003), and Dorich et al. (2013) 22

\footnotetext{
${ }^{20}$ The equations are presented in appendix 4.

${ }^{21}$ In the final-output sector value-added goods are combined with imported goods.

${ }^{22} \mathrm{We}$ also allow for rule-of-thumb wage setting.
} 
Monetary policy follows a Taylor-type rule that relates the policy rate to deviations of inflation from target and the output gap (defined as the deviation of output from its level under flexible prices and wages), as well as having the usual interest rate smoothing. We assume that the policymaker responds to a measure of inflation that excludes a transitory markup shock to reflect the MPC's narrative that they would "look through" temporary movements in inflation 23

Government spending and the rest-of-the-world model block are exogenous. The former is financed by lump-sum taxes. For the rest of the world, we specify a $\operatorname{VAR}(2)$ that includes measures of world GDP, world CPI inflation, and the world interest rate, in the same spirit as Adolfson et al. (2013). Sign restrictions - applied via the priors in the Bayesian estimation - are used to identify a world demand, world supply, and world monetary policy shock.

\subsection{Estimation}

We estimate our model with Bayesian techniques using data covering 1993:Q1 to 2016:Q2 24 To make the ex ante deflation-probability simulations more realistic, we adopt a recursive estimation procedure. This involves using real-time data and extending the sample by one quarter at a time, so allowing for potentially different parameter estimates for each quarter of our exercise 25

\footnotetext{
${ }^{23}$ For example, the November 2012 MPC minutes (MPC 2012, p. 9) state: "There were several factors that would probably cause inflation to remain somewhat above the $2 \%$ target for the next year or so: the continuing impact of the rise in university tuition fees, higher domestic gas and electricity prices, and increased fuel duties. There was little that monetary policy could do to influence those prices directly."

${ }^{24}$ The model's measurement equations are presented in appendix 4 . The start of our sample coincides with the adoption of the inflation-targeting regime, and we follow Burgess et al. (2013) in using data between 1987:Q2 and 1992:Q4, which were overwhelmingly affected by the 1992 exchange rate crisis, only to initialize the Kalman filter.

${ }^{25}$ We make three exceptions to this rule. First, for 2013:Q3 to 2014:Q2 we overwrite the investment data given data-quality issues at the time (with data from the 2014:Q3 vintage). Second, we do not have real-time estimates of the shadow rate for the entire period and so we construct measures based on the announced stock of asset purchases at the time, according to the method described later in this section. Third, real-time data for world CPI are not available before 2010:Q3,
} 
We estimate most of the parameters governing the business cycle properties of our model and calibrate the steady state based on sample averages, so that the model's great ratios, such as the labor share, may also vary as the sample size increases 26 For vintages of the model after 2008, we calibrate the productivity-growth trend to a higher rate before the financial crisis than after. We take this approach because the period of our sample that falls before the financial crisis (1993 to 2007) has particularly high average growth rates relative to a longer sweep of history (for example, since 1950). Making this adjustment might be thought of as capturing the sort of medium-term fluctuations in productivity growth described by Comin and Gertler (2006).

The fact that the headline policy rate was constant at 0.5 percent for a prolonged period in our sample (2009 onwards), while unconventional policy measures were adopted, presents our estimation with a challenge. To tackle this issue, we follow Fawcett et al. (2015) and include a measure of the shadow rate (similar to those considered by Krippner 2013 and $\mathrm{Wu}$ and Xia 2016) in place of the headline policy rate in our estimation. Our measure of the shadow rate is based on estimates of the effects of QE presented in Bridges and Thomas (2012). We view this approach as more appealing than the alternatives. Attempting to impose an ELB in our estimation would be impractical (and potentially misleading, by missing the effects of unconventional policy). Limiting the estimation sample to 2007 (as in Burgess et al. 2013) would omit the information contained in the post-2007 data and constrain our real-time estimation exercise.

\subsection{Stochastic Simulations}

To produce a model-based estimate of the probability of deflation, we conduct a stochastic-simulation exercise. The simulations involve, for each forecast date that we consider (2007:Q1 to 2016:Q2),

so, instead, we use CPI inflation in the M6 (the G-7 countries less the United Kingdom) as the observable.

${ }^{26} \mathrm{~A}$ notable exception is the calibration of the share of rule-of-thumb firms and workers. Given the difficulty of identifying them separately from the probabilities of adjusting prices or wages, we calibrate the shares to 20 percent for firms, based on evidence from Greenslade and Parker (2012), and to 40 percent for workers. 
producing three-year projections using the model (estimated on the relevant vintage of data), the conditioning assumption described below, and a large number of randomly drawn sequences of unanticipated shocks. We also account for parameter uncertainty by drawing parameter values from the posterior distributions that we obtain from our real-time estimation 27 The simulations provide a forecast density for each of the model's endogenous variables, at each forecast origin. The time series for the simulated deflation probabilities are calculated by computing the proportion of the forecast distribution for annual CPI inflation that is negative for each forecast vintage.

\subsubsection{Base Forecasts}

Our conditioning assumption for the "base" forecasts is to center them, for each forecast vintage, on the MPC's projections for CPI inflation, GDP growth, and the market path for Bank Rate (reported in appendix 1) 28 This is broadly similar to the conditioning approach used by Coenen and Warne (2014) 29 Conditioning the projections adds greater realism to the exercise relative to using unconditional forecasts because it incorporates information known at the time that the model misses (e.g., expectations for oil prices), and a slower reversion to steady state than our model estimates would imply (reflecting the prevalence of pre-crisis data in our sample). Conditional forecasts are, therefore, likely to give a more realistic picture of the persistence of the headwinds facing the economy over this period.

To construct these conditional forecasts, we use the model to compute a set of structural shocks consistent with the MPC's projections. To do so, we invert the model on the three IR forecasts using all of its shocks (except for the monetary policy shock) under

\footnotetext{
${ }^{27}$ This is in line with the analysis of Chung et al. (2012) for their simulation of the Smets and Wouters (2007) model.

${ }^{28}$ The MPC's forecasts typically report annual inflation and annual GDP growth. However, given the quarterly nature of the model, we condition on the quarterly rates for these variables.

${ }^{29}$ Coenen and Warne (2014) condition their simulations on forecast vintages provided by Consensus Economics. We condition on the IR projections given that they are readily available to the public, cover a consistent horizon for each forecast vintage, and have practical benefits in terms of their compatibility with our model, including the existence of real-time data sets for all of its observables.
} 
the assumption that they are anticipated by agents 30 For each of the base forecasts, we use the version of the model estimated on real-time data to that point, and the vintage of back data available at the time.

\subsubsection{Stochastic Simulation}

With the base central forecasts in hand, we characterize the densities by conducting our stochastic simulations under two alternative assumptions about the ability of monetary policy to respond to shocks. First, we assume that policy is unconstrained. In response to a shock, the policy rate adjusts as implied by the rule in the model. This implies that there is no limit to how much the policy rate could be cut in response to adverse shocks, which we view as being consistent with the MPC's being able to use unconventional policy, such as QE, to achieve the monetary stimulus prescribed by the rule 31 Second, we assume that the policy rate cannot be cut below an ELB of 0.5 percent. In other words, in this case, unconventional policy is assumed to be potentially unable to deliver the accommodation implied by the rule 32

To impose the ELB, we use the piecewise-linear shadow-price shocks approach of Holden and Paetz (2012). The overall procedure in which we embed this step has similarities to the one outlined in Guerrieri and Iacoviello (2015). While agents may expect the ELB to bind in some future period, and adjust their behavior accordingly, the linearity assumption behind both approaches implies that neither captures any precautionary motives associated with the risk

\footnotetext{
${ }^{30}$ The over-identified inversion approach is described in appendix $\mathrm{C}$ of Burgess et al. (2013). Appendix 2 discusses how the conditioning assumptions used in our base forecast do not affect our assessment of the probability of deflation and provides robustness checks.

${ }^{31}$ Since our model lacks an explicit role for unconventional policies, this, in effect, assumes that the impact of unconventional policies can be translated into a change in the short-term nominal interest rate, consistent with the logic of the shadow rate approach of Krippner (2013) and Wu and Xia (2016).

${ }^{32}$ In the working paper version of the paper (Haberis, Masolo, and Reinold 2016), we also report results for simulations in which the ELB is set at zero. The results lie between the two and are generally closer to the simulations in which policy is unconstrained (suggesting that for most shocks, relatively little additional space for loosening would be required for the ELB not to present a constraint).
} 
that the ELB might bind. That said, our approach applies more readily to a model of this size compared with the alternatives that do allow for such effects, such as that proposed by Fernández-Villaverde et al. (2015) 33

\section{Results}

\subsection{Simulated Deflation Probabilities}

We can now turn to the deflation probabilities implied by our stochastic simulations under the different assumptions about the constraints on monetary policy. By combining these with the external estimates presented in section 3 , we are able to infer agents' perceptions about the effectiveness of monetary policy since 2007. The probabilities of deflation from our simulations at the one-, two-, and three-year horizons are plotted in figure 3, alongside the external estimates. The dashed lines show the deflation probabilities in our simulations assuming that policy is unconstrained; the dash-dotted lines show the deflation probabilities when policy is constrained.

Two findings in figure 3 are noteworthy. First, the simulated probability of deflation when we assume that policy was unconstrained is broadly in line with the external estimates, which shows that our model and simulation approach can accurately capture the evolution of the probability of deflation over our sample. This is the case for both the overall level and its changes, and for each forecast horizon 34 The model-based estimates show peaks in deflation probability around 2009 and 2015, particularly in the first year of the projections, but also more persistently for the 2009 episode.

Second, there are divergences between the simulated probabilities of deflation under the alternative assumptions about the constraints on policy that allow for inference about perceptions of policy effectiveness in the external estimates. Specifically, simulations under the ELB constraint imply a probability of deflation over late 2011 to 2013 (and, to a lesser extent, in 2015 at all horizons) that is

\footnotetext{
${ }^{33}$ For further details on the implementation, see appendix 3 .

${ }^{34}$ As discussed in section 3 , the level of deflation probability from the SEF is systematically lower than that for the other estimates. That said, it is the changes in the estimates that are key for our exercise.
} 


\section{Figure 3. Simulated and External Estimates of Deflation Probability}
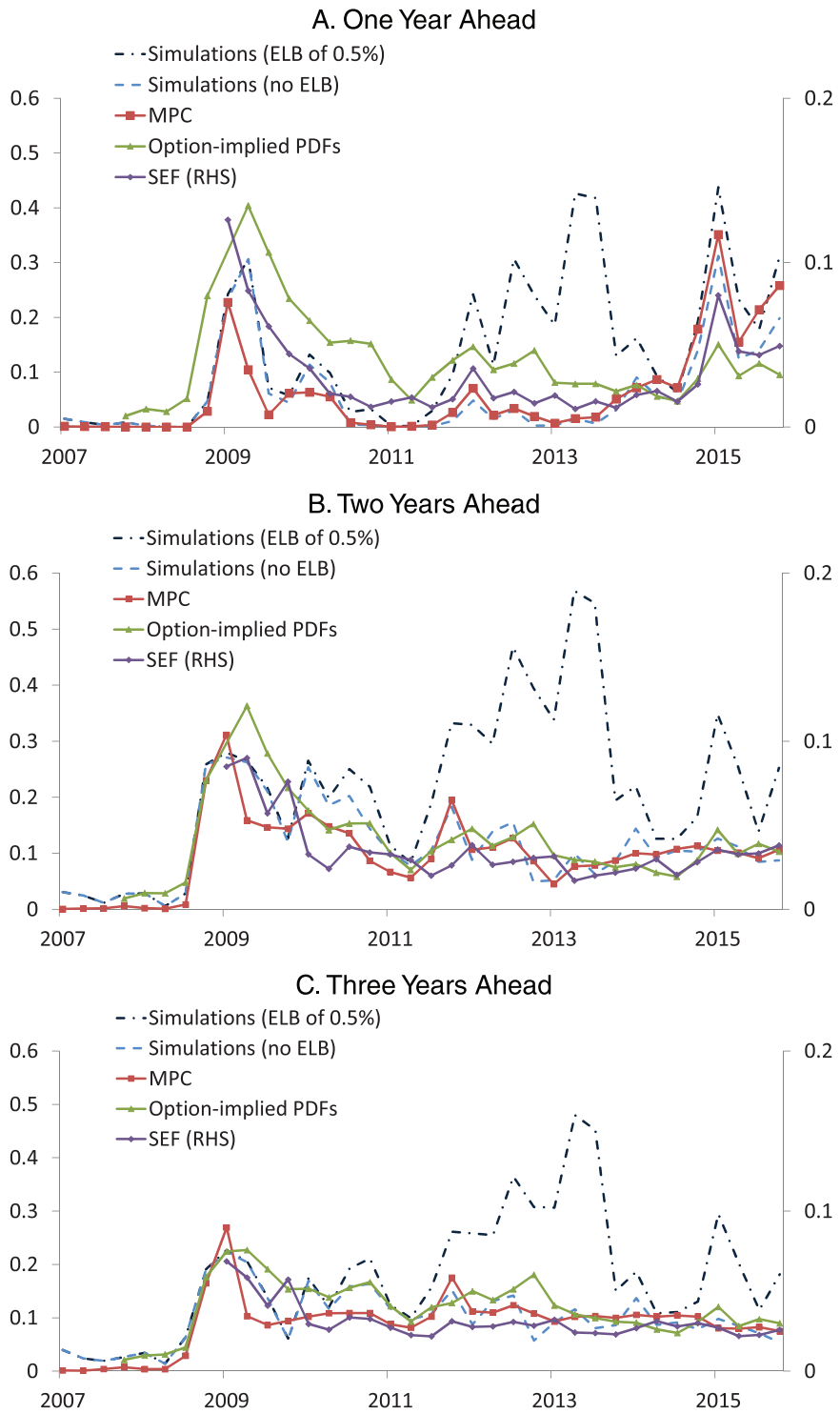

Notes: See notes to figure 2 . 
substantially higher than in the external estimates. Assuming that the ELB was binding, our simulations would have implied a rise in deflation probabilities of 30 to 50 percentage points at all horizons in late 2011 to 2013 , and of 10 to 15 percentage points at years 2 and 3 in 2015. In both cases, however, the external estimates of deflation probabilities stayed broadly unchanged.

Taken together, these results suggest that the agents behind the external estimates - the MPC itself, financial market participants, and the professional forecasters in the SEF - did not perceive monetary policy to have been particularly constrained 35 In the remainder of this section, we use our model and the simulation results to shed light on the factors behind the heightened deflation-probability episodes and, in particular, what makes the late-2011 to 2013 period special.

\subsection{Discussion: Drivers of Heightened Deflation Probability}

The two key drivers of heightened deflation probability in the different episodes of the simulations are (i) the inflation forecast and (ii) the scope for monetary loosening, as reflected by the gap between the market path for interest rates and the level of the ELB. The role of the former is clear: when inflation is expected to be low, it takes relatively small disinflationary shocks to lead to deflation. On the latter, there needs to be room for the policy rate to fall to counteract a disinflationary shock throughout the forecast horizon. If agents expect policy rates to be constrained by the ELB today or at some point in the future, that raises their expectation for future policy rates relative to the case in which policy does not face an ELB. This leads them to rein back spending by more, which in turn increases the deflationary pressure 36

${ }^{35}$ This conclusion depends on our model being a reasonable description of the U.K. economy. As discussed, the fact that the simulated deflation probabilities under unconstrained policy align with the external estimates gives us confidence that the model provides an empirically reasonable representation of the transmission mechanism of monetary policy in the United Kingdom.

${ }^{36}$ As discussed in section 4.3 , we implement the stochastic simulations with unanticipated shocks. However, the effects of the ELB are anticipated by agents in the model, even if the policy rate only reaches the ELB in some future quarter. This is because the dynamics in the model, both in terms of the shock processes 


\section{Table 1. Inflation Forecasts and Market Path across Deflation Episodes}

\begin{tabular}{|l|c|c|c|}
\hline & $\mathbf{2 0 0 9}$ & $\begin{array}{c}\text { Late 2011 } \\
\text { to 2013 }\end{array}$ & $\mathbf{2 0 1 5}$ \\
\hline Modal Inflation Forecast (\%) & & & \\
Average over First Year & 1.3 & 2.8 & 0.3 \\
Average over Second Year & 1.1 & 2.0 & 1.6 \\
Average over Third Year & 1.2 & 1.8 & 2.1 \\
Market Path & 0.7 & 0.5 & 0.5 \\
Average over First Year & 2.0 & 0.5 & 0.8 \\
Average over Second Year & 3.2 & 0.7 & 1.2 \\
Average over Third Year & $2009: \mathrm{Q} 1-$ & $2011: \mathrm{Q} 4-$ & $2015: \mathrm{Q} 1-$ \\
Memo: Dates & $2009: \mathrm{Q} 3$ & $2013: \mathrm{Q} 4$ & $2015: \mathrm{Q} 4$ \\
\hline
\end{tabular}

The higher deflation probability associated with forecasts made in 2009 reflected the expectation at the time that inflation would remain low over the next three years (table 1, first column). As has been described in section 2 , this reflected a view that the temporary upward pressures from the depreciation of sterling and the hike in VAT would be outweighed by a more persistent drag from domestic demand. Figure 4 shows that a decomposition of key variables into the contribution from the model's structural shocks tells a very similar story about the key forces on inflation over this period (as captured by the exchange rate risk premium, markup, and domestic demand shocks) 37 While a weak inflation outlook did contribute to heightened deflation probability over this period, the scope for

and the structural equations, mean that the policy rate can be pushed to the ELB in the future (typically one or two quarters ahead), even if it is not in the quarter that the shock hits.

${ }^{37}$ For convenience, we plot the decomposition from the most recent vintage in our real-time database, 2016:Q2. The effects of the structural shocks are uncovered using the Kalman smoother. Given that we condition the model's baseline forecasts for key variables like inflation and the policy rate in our simulations, the model's interpretation of the shocks over the past does not directly affect the probability of deflation in our exercise. However, we find it reassuring that it offers a similar narrative for the key economic drivers to the external discussion presented in section 2. Moreover, understanding these drivers can help us to 


\section{Figure 4. Shock Decomposition of Inflation, Output Gap, and Policy Rate}

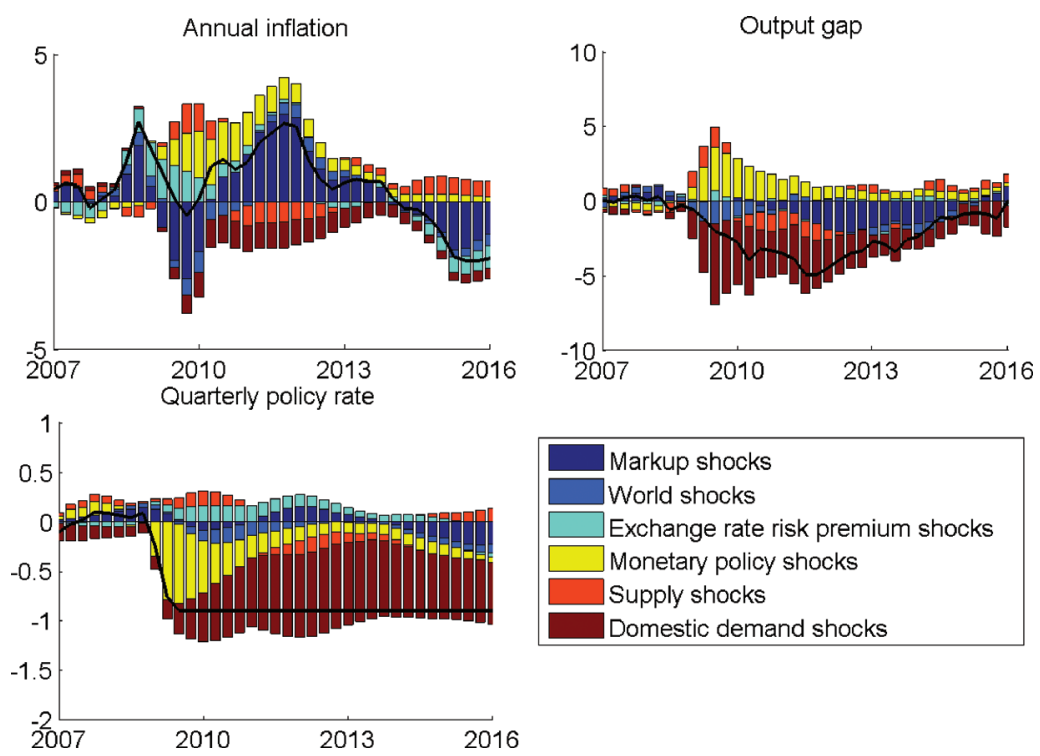

Notes: Charted in deviations from steady state. The output gap is defined as the difference between output and its counterpart, assuming that all prices and wages are flexible. Based on the model and data as of May 2016 (the end of our sample).

loosening did not. In the first quarter of 2009, policy rates had yet to hit 0.5 percent, and afterwards the market path was relatively steep, with policy rates expected to return to a little over 3 percent within three years (table 1, first column). As a result, even with a constraint, there would have been plenty of room to loosen in response to adverse shocks. Therefore the probability of deflation implied by our simulations under constrained and unconstrained policy was very similar.

The late-2011 to 2013 episode, by contrast, corresponded to a period in which inflation was expected to be at or above target, while the market path was extremely flat. Over the course of the

understand some of the factors that would have influenced the MPC's forecasts on which we condition (although as described in section 4.3, when producing their forecasts, the MPC draws on other information that is missing from the model). 
forecasts made during this episode, the conditioning path for policy rates was expected to increase by only around 0.2 percentage points from its starting point of 0.5 percent (table 1 , second column). The model identifies a sequence of markup shocks as pushing up on inflation over this period (figure 4), consistent with the narrative for inflation at the time, discussed in section 2 , that focused on temporary factors. These were expected to fade fairly quickly, with the MPC's inflation forecasts returning to target within a year or two (table 1). These overshoots of the inflation target came despite an output gap that bottomed out at close to -5 percent.

In our simulations in which policy is constrained, there is a large and prolonged increase in deflation probability during this episode, despite relatively high inflation. This reflects the limited scope for monetary policy to counteract disinflationary shocks implied by the small gap between the market path and the ELB. The effects of the limited scope for monetary loosening can be seen in figure 5 , which plots the forecast distributions (shown as fan charts) from our stochastic simulations for annual CPI inflation, quarterly real GDP growth, and Bank Rate around the example of the November 2013 MPC forecast under the assumptions that there is no ELB (left-hand column) and that there is an ELB of 0.5 percent (righthand column). In the case in which policy is constrained by the ELB, there are large downward skews in the forecast distributions for inflation (and GDP growth), which are consistent with a greater probability of deflation in these projections.

The fact that the external estimates of deflation probability do not show an increase during this period suggests that there was confidence in the ability of monetary policy to provide extra policy stimulus if necessary. This may have been via increased use of unconventional measures, or by cutting Bank Rate from 0.5 percent.

In 2015, both low expected inflation and a flat market path played a role in the heightened probability of deflation in our simulations, although at different horizons. At short horizons, the weak inflation outlook was more significant, as shown by the increased deflation probability in the model-based estimates under both assumptions about the constraints on policy. At this time, inflation was well below target, which the model attributes, broadly, to a sequence of negative markup and exchange rate risk premium shocks. This is again consistent with the commentary discussed in 


\section{Figure 5. Fan Charts for Simulations Centered on November 2013 IR Forecasts}

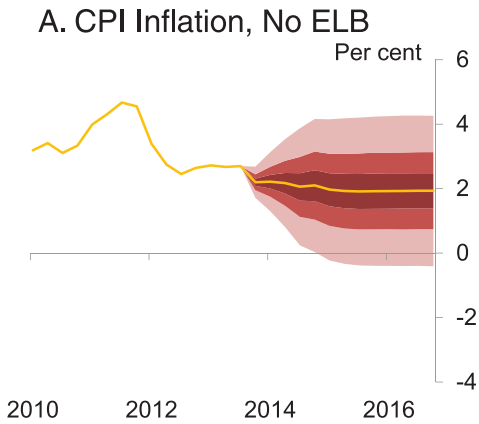

D. CPI Inflation, $0.5 \%$ ELB

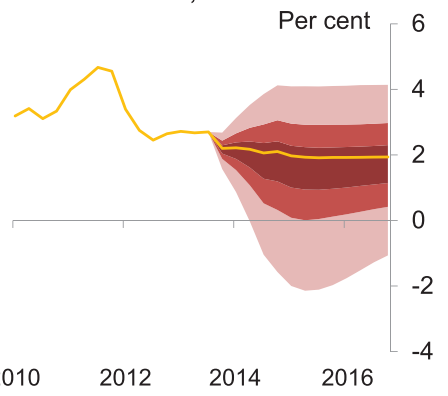

B. Quarterly GDP Growth, No ELB

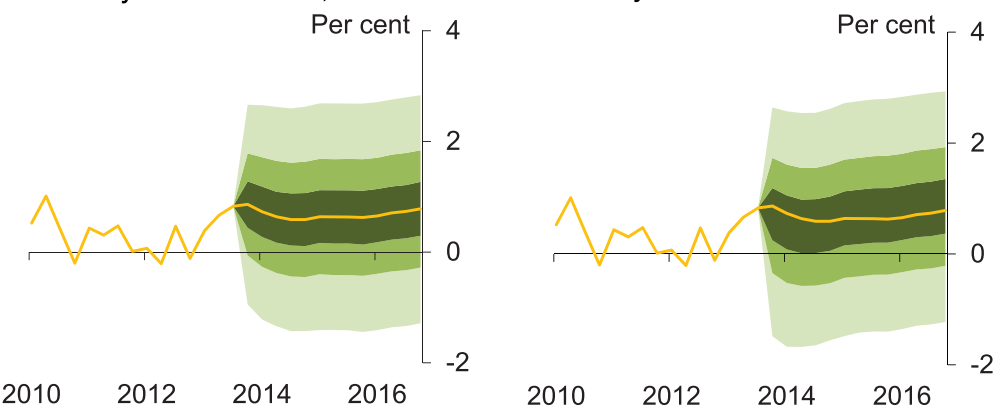

C. Bank Rate, No ELB

F. Bank Rate, 0.5\% ELB
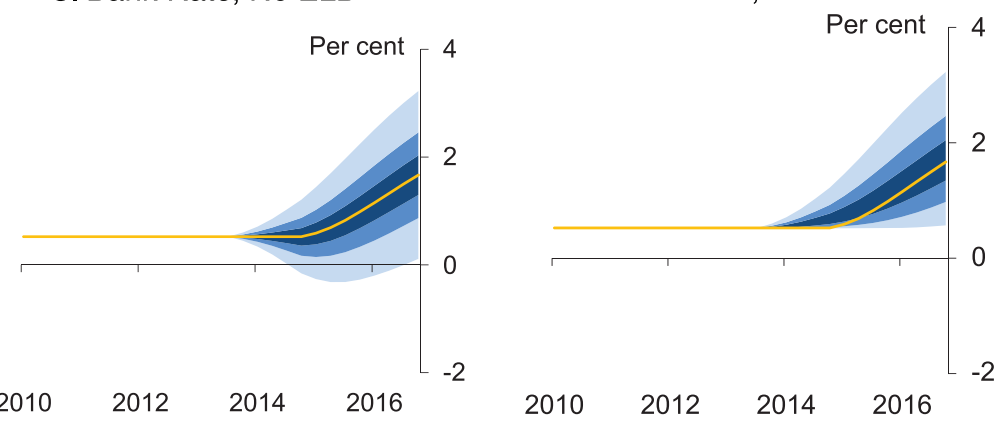

Notes: Each pair of shaded bands represents 30 percent of simulated paths. The yellow line (see online version at http://www.ijcb.org for colors) plots the central projection from the November 2013 Inflation Report forecast around which the simulations are centered. The mean forecast in our simulated distributions is only centered on the IR forecast when policy is unconstrained. 
section 2 that linked the weak inflation outlook to the effects of falling energy prices and an appreciation of sterling. Further out, however, inflation was expected to return to target (table 1, third column). The heightened deflation probability in our simulations under constrained policy for the second and third year of the projections, therefore, reflects the flatness of the market path limiting the scope for policy to respond to deflationary shocks. From its starting point of 0.5 percent, Bank Rate was expected to rise by around 0.7 percentage points over the three-year forecast horizon for projections made during this episode. That external deflation-probability estimates were not raised at this horizon is thus further corroborative evidence that unconventional policies were deemed effective.

\section{Conclusions}

There are several reasons to suppose that the effectiveness of U.K. monetary policy to keep inflation at target might have been doubted in the period since the 2007 to 2008 financial crisis. First, the United Kingdom experienced a fall in output that was among the largest among advanced economies. Second, given the United Kingdom's high degree of openness, inflation is arguably harder to control on account of the effects of the exchange rate compared with economies that are more closed. Third, the Bank of England implemented a particularly broad array of unconventional measures from early on in the crisis.

This paper considers perceptions about the scope for monetary loosening since 2007 by comparing the deflation probabilities implied by simulations of an estimated DSGE model, under alternative assumptions about the constraints on monetary policy, with those expected by policymakers, financial markets, and professional forecasters. In these groups' assessments, the probability of deflation was heightened around 2009 and in 2015. These episodes are also evident in our model-based estimates when we assume that policy is unconstrained. Although our model contains a number of simplifications (such as abstracting from an explicit role for unconventional monetary policy or financial frictions), the fact that the simulated deflation probabilities when policy is unconstrained track fairly closely the three external estimates provides reassurance that it is an empirically reasonable representation of the monetary transmission mechanism in the United Kingdom. By contrast, when we 
assume that monetary policy is constrained in its ability to offset the effects of deflationary shocks by imposing an ELB on policy rates of 0.5 percent, we also identify an additional episode of heightened deflation probability in late 2011 to 2013 . That this episode is inconsistent with the external estimates of deflation probability suggests that monetary policy was not perceived to have been constrained.

Faced with the possibility that global real interest rates will remain persistently lower than pre-crisis levels (for example, Laubach and Williams 2016), policymakers may find themselves calling on unconventional policy measures more often in the future. To the extent that the experience since 2007 offers a good guide, our results offer some reassurance that such measures are considered an effective means of counteracting deflationary shocks by a range of economic participants.

\section{Appendix 1. Selected Inflation Report Forecasts}

\section{Figure 6. Inflation Report Forecasts for Inflation, GDP Growth, and Interest Rates}
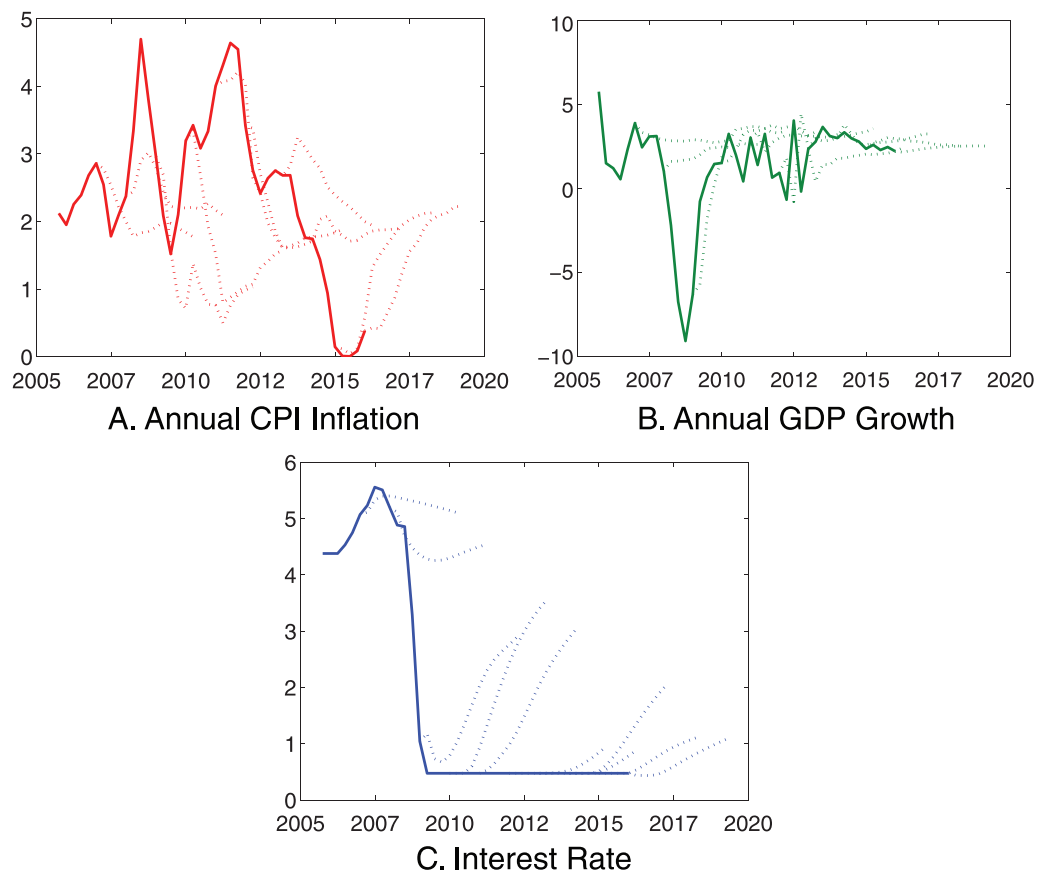

Notes: Solid lines report data. Dashed lines report forecasts for annual inflation, annual GDP growth, and the interest rate produced in quarter 1 of 2006 to 2016. 


\section{Appendix 2. Alternative Conditioning Assumptions}

As described in section 4.3, we use a conditioning assumption that centers our projections on the MPC's forecasts in the IR. We do so by inverting the model on the IR projections using a subset of its shocks. In this appendix, we describe the implications of alternative conditioning assumptions to produce this "base" forecast.

The key point is that these alternative assumptions have no impact on our simulated deflation probabilities. This is because the stochastic simulations are implemented as a marginal simulation around the base (consistent with the approach of Coenen and Warne 2014). As explained in section 5, the key factors affecting the probability of deflation in our simulations are the outlook for inflation and the position of the market path vis-à-vis the ELB, both of which are conditioned in our base to match the IR forecasts. As such, the structural shocks computed in our inversion will not affect the levels of these variables.

The structural shocks calculated in the inversion can, however, have implications for the narrative in the base and, in particular, the path for the model's latent variables such as the output gap and the policy rule. However, as we will show, these changes in narrative are modest. To illustrate the effect of alternative assumptions, we use the forecast from May 2016 as an example. We start by presenting the shock extraction we use for our main results, before turning to two alternative assumptions: first, using a measure of Bank Rate adjusted for the effects of unconventional policy (the "shadow rate," as described in section 4.2) as the policy rate observable; and second, including monetary policy shocks in the conditioning of the base.

\section{May 2016 Base}

For our main results we use all of the model's shocks except for the monetary policy shock. Figure 7 plots the model's shocks in terms of their contribution to annual CPI inflation, the (flexible-price) output gap, and the quarterly policy rate 38

\footnotetext{
${ }^{38}$ That there are contributions from the monetary policy shock to the policy rate over the forecast reflects the gradual unwinding of the monetary policy shocks identified by the Kalman smoother.
} 


\section{Figure 7. Shock Decomposition of May 2016 Simulation Base}
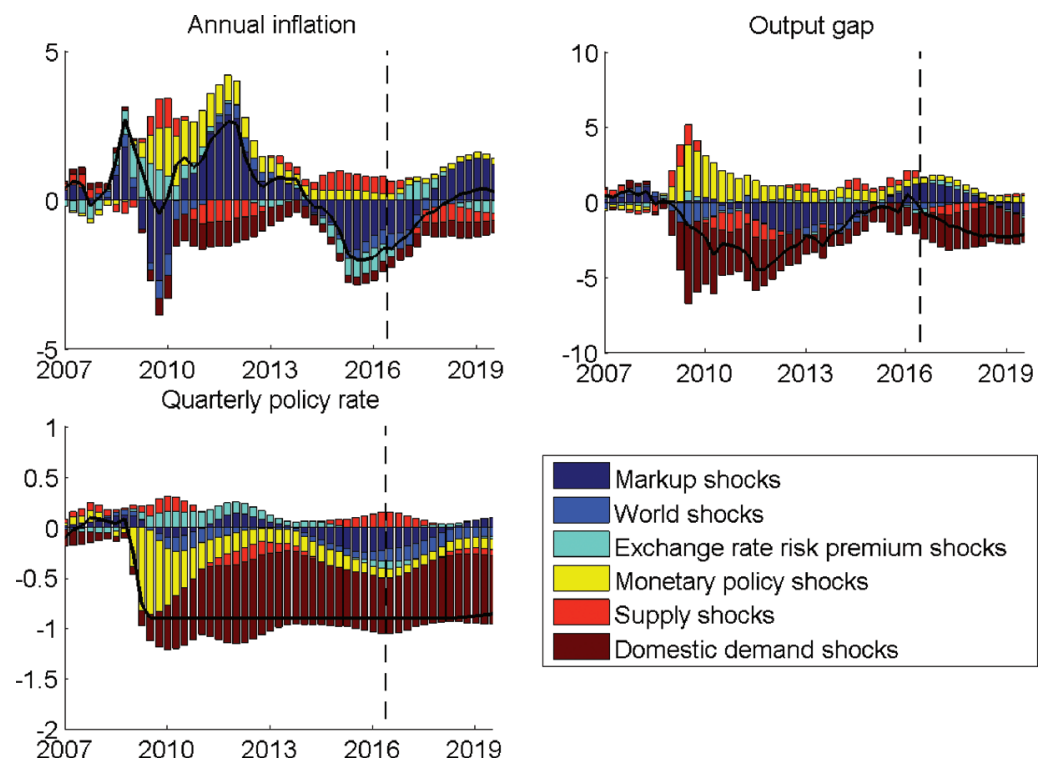

Notes: Charted in deviations from steady state. Based on the model and data as of May 2016. The shocks over the past (to the left of the vertical dotted line) are extracted using the Kalman smoother. The shocks over the forecast are computed via the inversion.

Section 5.2 described the role of different shocks in a variant of this figure that did not include the forecast (figure 4), which we will not repeat here. But the model's interpretation of monetary policy in the data warrants further attention. The yellow bars in the explanation of the policy rate over the past indicate that the model interprets monetary policy as having loosened by more than a rule estimated on past behavior would have prescribed, particularly at the onset of the crisis (see online version at http://www.ijcb.org for colors). That reflects that the high degree of smoothing in the monetary policy rule (useful for describing intertial monetary policy in normal times) does not capture the pace of loosening in this crisis situation. The implication is that the model's policy rule is a little above Bank Rate's floor of 0.5 percent annually over this period. 
Figure 8. Shock Decomposition of May 2016 Simulation Base (policy rate including shadow effects of QE)
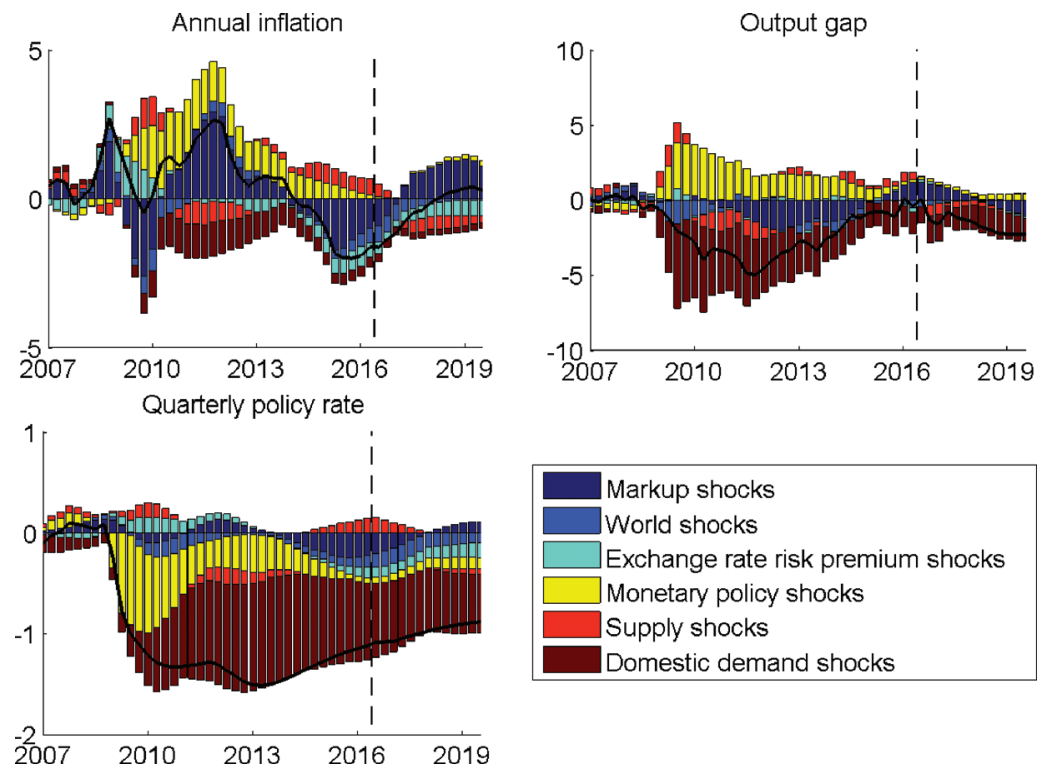

Notes: See notes to figure 7.

\section{May 2016 Base Using a Shadow Policy Rate}

Figure 8 is analogous to figure 7 , but it includes the shadow rate (which attempts to map the effects of QE into policy rate space) as the observable for the policy rate. Negative monetary policy shocks are again needed to explain how loose policy has been since the crisis and the speed of the loosening at the onset of the crisis. However, the monetary policy rule is now materially negative. The relative contributions of other shocks are, however, little changed 39

\footnotetext{
${ }^{39}$ Again, while no monetary policy shocks are used in the inversion over the forecast, the effects of monetary policy shocks identified over the past still feed through to variables over the forecast period.
} 
Figure 9. Shock Decomposition of May 2016 Simulation Base (monetary policy shocks included in inversion)
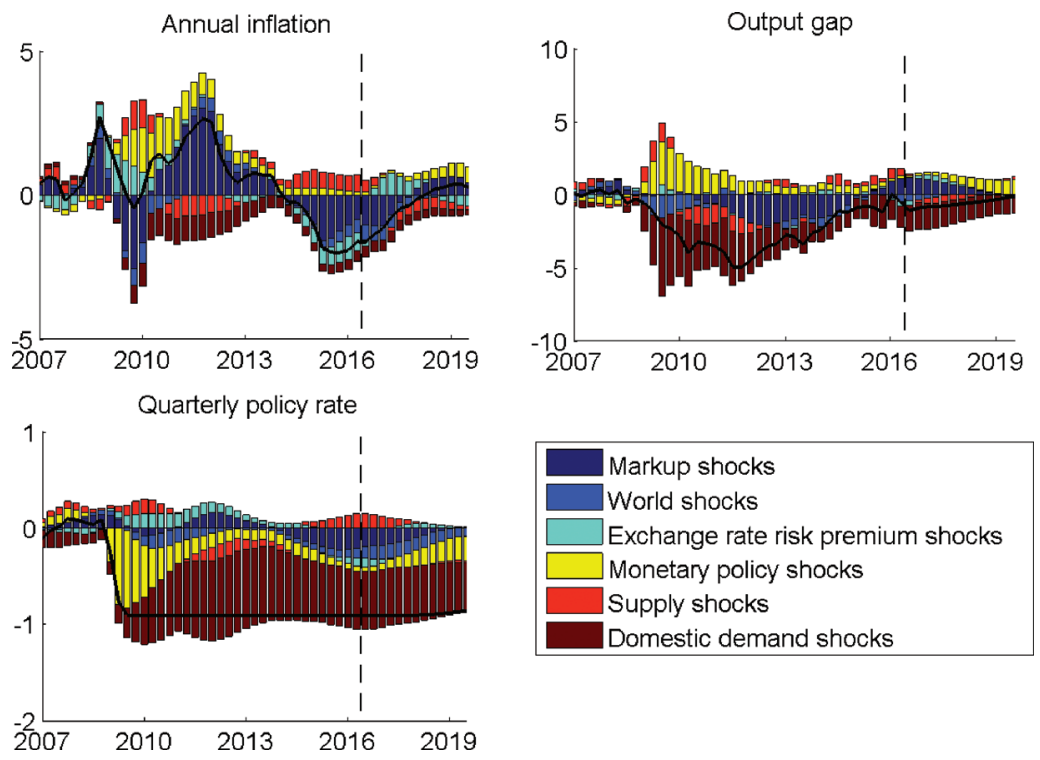

Notes: See notes to figure 7.

May 2016 Base with Monetary Policy Shocks in the Inversion

Figure 9 shows the equivalent shock decompositions with an observable for the policy rate as Bank Rate, but with monetary policy shocks included in the inversion on the IR forecasts. This generates two differences. First, the model attributes more of the flatness of the market path to negative monetary policy shocks and identifies relatively less negative other domestic demand shocks. Second, rather than a negative output gap opening up over the forecast, as when monetary policy shocks are excluded, the output gap remains broadly closed.

\section{Appendix 3. Stochastic Simulation}

Without an ELB

When monetary policy is not assumed to be constrained by an ELB, producing stochastic simulations is straightforward. It involves 
using the model's rational expectations solution to project forward an $H$-quarter-long (in our case thirteen) sequence of unanticipated shocks (except the monetary policy shocks) around the base forecast from an initial condition. These shocks are drawn from a normal distribution with mean zero and the shocks' estimated standard deviations. This process is repeated a large number of times $(2,000)$ for fifty different parameter sets drawn from the posterior distribution, to give a distribution of 100,000 forecasts. This results in (broadly) symmetric fan charts centered on the baseline forecasts, where the width of the fan is determined by the standard deviations of the shocks in the model 40 To illustrate this point, fan charts without an ELB imposed can be found in the first column of figure 5 .

\section{With an $E L B$}

In producing stochastic simulations with a binding ELB, we impose the constraint using the approach of Holden and Paetz (2012). The starting point is a linear rational expectations model, for which the structural equations for the endogenous variables, $x_{t}$, can be written as

$$
H^{F} \mathbb{E}_{t} x_{t+1}+H^{C} x_{t}+H^{B} x_{t-1}=\Psi z_{t} .
$$

To separate the monetary policy rule for the nominal interest rate $r_{t}$ from the other variables (denoted by $\tilde{x}_{t}$ ), the model can be partitioned as follows:

$$
\begin{gathered}
{\left[\begin{array}{cc}
H_{\tilde{x} \tilde{x}}^{F} & H_{\tilde{x} r}^{F} \\
0 & 0
\end{array}\right] \mathbb{E}_{t}\left[\begin{array}{l}
\tilde{x}_{t+1} \\
r_{t+1}
\end{array}\right]} \\
+\left[\begin{array}{cc}
H_{\tilde{x} \tilde{x}}^{C} & H_{\tilde{x} r}^{C} \\
-\left(1-\rho_{r}\right) H_{r \tilde{x}}^{C} & 1
\end{array}\right]\left[\begin{array}{c}
\tilde{x}_{t} \\
r_{t}
\end{array}\right]+\left[\begin{array}{cc}
H_{\tilde{x} \tilde{x}}^{B} & H_{\tilde{x} r}^{B} \\
0 & -\rho_{r}
\end{array}\right]\left[\begin{array}{c}
\tilde{x}_{t-1} \\
r_{t-1}
\end{array}\right] \\
=\left[\begin{array}{cc}
\Psi_{\tilde{x} \tilde{x}} & 0 \\
0 & \sigma_{r}
\end{array}\right]\left[\begin{array}{c}
z_{t}^{\tilde{x}} \\
z_{t}^{r}
\end{array}\right],
\end{gathered}
$$

where $z_{t}^{r}$ is the monetary policy shock and $z_{t}^{\tilde{x}}$ are the other shocks in the model. In addition, we are imposing that the policy rule takes

\footnotetext{
${ }^{40}$ Asymmetric posterior parameter distributions mean that the fan charts are not completely symmetric.
} 
the form of a Taylor rule with smoothing (given by $\rho_{r}$ ); $\sigma_{r}$ denotes the standard deviation of the policy shock.

When the nominal interest rate cannot go below a certain value, $b$ (an ELB), the policy rule is a non-linear equation that has the following form:

$$
r_{t}=\max \left\{b, \rho_{r} r_{t-1}+\left(1-\rho_{r}\right) H_{r \tilde{x}}^{C} \tilde{x}_{t}+\sigma_{r} z_{t}^{r}\right\} .
$$

For the purposes of the implementation, this will be replaced with

$$
r_{t}=\rho_{r} r_{t-1}+\left(1-\rho_{r}\right) H_{r \tilde{x}}^{C} \tilde{x}_{t}+\sum_{s=0}^{H} z_{t+s}^{r},
$$

where $z_{t+s}^{r}$, for $s \geq 0$, are the shadow-price shocks that ensure that the constraint $b$ is respected (and which are anticipated by agents in the model). The solution minimizes the size of the anticipated shocks needed to enforce the ELB, subject to additional criteria: the shadow-price shocks can only be positive (they can only increase the interest rate) and the shadow-price shock at a particular horizon can only be non-zero if the bound binds at that horizon. That is, the shocks are the optimum of a quadratic programming problem.

The approach is incorporated into the stochastic simulation on a period-by-period basis, which ensures that the shocks used to impose the ELB are anticipated only once the (unanticipated) shocks that have driven the policy rate to the ELB have hit. A stochastic simulation for $H$ periods subject to the ELB, therefore, can be constructed by combining $H$ perfect foresight projections from an initial condition that is updated sequentially with the unanticipated shocks, to move from forecast period 0 to forecast period $H-1$. The steps proceed as follows:

(i) In the first period, a projection absent the ELB is produced from a random draw of the shocks in that period around the base forecast from an initial condition (period 0).

(a) If the interest rates implied by the policy rule are below the ELB, solve for the (potentially large) sequence of anticipated monetary policy shocks that enforce the ELB. 
(b) If the ELB is not binding, the vector of anticipated monetary policy shocks would be equal to zero.

(ii) Update the projection with this sequence of anticipated monetary policy shocks and retain the endogenous variables in the first period.

(iii) Repeat these steps in the second period using the endogenous variables from the previous period as the initial condition, and continue to produce an $H$-quarter projection subject to the ELB.

\section{Appendix 4. Model Equilibrium Conditions}

The model equations in this section are written in log-deviations from steady-state values. For example, $c_{t}$ denotes the log-deviation of consumption from steady state at date $t . c_{t} \equiv \log C_{t}-\log C$, where $C_{t}$ is the level of detrended consumption and $C$ is the steady-state value of detrended consumption. The detrended value of consumption is defined as $C_{t} \equiv \frac{\tilde{C}_{t}}{\tilde{\chi}_{t}^{Z}}$, where $\tilde{C}_{t}$ is the level of consumption at date $t$ and $\tilde{\chi}_{t}^{Z}$ is the stochastic trend of consumption. The stochastic trend includes the deterministic trends in the model, as well as the effects of the exogenous population and labor-augmenting productivity (LAP) trends 41

\section{Behavioral Equations}

Final-output production function:

$$
z_{t}=\alpha_{V} v_{t}+\left(1-\alpha_{V}\right) m_{t}
$$

Value-added demand:

$$
m c_{t}^{Z}=p_{t}^{V}+v_{t}-z_{t}-\frac{\left(1-\alpha_{V}\right)}{\alpha_{V}} \psi_{M}\left(\frac{M}{V}\right)^{2}\left(m_{t}-v_{t}\right) .
$$

\footnotetext{
${ }^{41}$ In particular, $\log \tilde{\chi}_{t}^{Z}=\log \Gamma^{Z}+\log \tilde{\chi}_{t-1}^{Z}+\gamma_{t}^{Z}$, where $\gamma_{t}^{Z}$ is stochastic and defined below.
} 
Import demand:

$$
m c_{t}^{Z}=p_{t}^{M}+m_{t}-z_{t}+\hat{\varepsilon}_{t}^{M}+\psi_{M}\left(\frac{M}{V}\right)^{2}\left(m_{t}-v_{t}\right)
$$

Value-added production function:

$$
v_{t}=\left(1-\alpha_{L}\right) k_{t-1}+\alpha_{L} l_{t}+\hat{\varepsilon}_{t}^{T F P} .
$$

Labor demand:

$$
m c_{t}^{V}=w_{t}+l_{t}-p_{t}^{V}-v_{t} .
$$

Capital demand:

$$
m c_{t}^{V}=r_{t}^{K}+k_{t-1}-p_{t}^{V}-v_{t}-\gamma_{t}^{Z} .
$$

Final-output inflation:

$$
\begin{aligned}
\pi_{t}^{Z}= & \hat{\mu}_{t}^{Z}+\hat{\mu}_{t}^{Z, t e m p}+\frac{\left(1-\phi_{Z}\right)\left(1-\phi_{Z} \beta \Gamma^{H}\right)\left(1-\omega_{Z}\right)}{\phi_{Z}\left(1+\xi_{Z} \beta \Gamma^{H}\right)+\left(1-\phi_{Z}\right) \omega_{Z}} m c_{t}^{Z} \\
& +\frac{\xi_{Z}\left(\phi_{Z}+\left(1-\phi_{Z}\right) \omega_{Z}\right)}{\phi_{Z}\left(1+\xi_{Z} \beta \Gamma^{H}\right)+\left(1-\phi_{Z}\right) \omega_{Z}} \pi_{t-1}^{Z} \\
& +\frac{\phi_{Z} \beta \Gamma^{H}}{\phi_{Z}\left(1+\xi_{Z} \beta \Gamma^{H}\right)+\left(1-\phi_{Z}\right) \omega_{Z}} \mathbb{E}_{t} \pi_{t+1}^{Z} .
\end{aligned}
$$

Value-added inflation:

$$
\begin{aligned}
\pi_{t}^{V}= & \hat{\mu}_{t}^{V}+\frac{\left(1-\phi_{V}\right)\left(1-\phi_{V} \beta \Gamma^{H}\right)\left(1-\omega_{V}\right)}{\phi_{V}\left(1+\xi_{V} \beta \Gamma^{H}\right)+\left(1-\phi_{V}\right) \omega_{V}} m c_{t}^{V} \\
& +\frac{\xi_{V}\left(\phi_{V}+\left(1-\phi_{V}\right) \omega_{V}\right)}{\phi_{V}\left(1+\xi_{V} \beta \Gamma^{H}\right)+\left(1-\phi_{V}\right) \omega_{V}} \pi_{t-1}^{V} \\
& +\frac{\phi_{V} \beta \Gamma^{H}}{\phi_{V}\left(1+\xi_{V} \beta \Gamma^{H}\right)+\left(1-\phi_{V}\right) \omega_{V}} \mathbb{E}_{t} \pi_{t+1}^{V}
\end{aligned}
$$


Import price inflation:

$$
\begin{aligned}
\pi_{t}^{M}= & \hat{\mu}_{t}^{M}+\frac{\left(1-\phi_{M}\right)\left(1-\phi_{M} \beta \Gamma^{H}\right)\left(1-\omega_{M}\right)}{\phi_{M}\left(1+\xi_{M} \beta \Gamma^{H}\right)+\left(1-\phi_{M}\right) \omega_{M}}\left(p_{t}^{X^{F}}-q_{t}-p_{t}^{M}\right) \\
& +\frac{\xi_{M}\left(\phi_{M}+\left(1-\phi_{M}\right) \omega_{M}\right)}{\phi_{M}\left(1+\xi_{M} \beta \Gamma^{H}\right)+\left(1-\phi_{M}\right) \omega_{M}} \pi_{t-1}^{M} \\
& +\frac{\phi_{M} \beta \Gamma^{H}}{\phi_{M}\left(1+\xi_{M} \beta \Gamma^{H}\right)+\left(1-\phi_{M}\right) \omega_{M}} \mathbb{E}_{t} \pi_{t+1}^{M} .
\end{aligned}
$$

Export price inflation:

$$
\begin{aligned}
\pi_{t}^{E X P} & \\
= & \hat{\mu}_{t}^{E X P}+\frac{\left(1-\phi_{E X P}\right)\left(1-\phi_{E X P} \beta \Gamma^{H}\right)\left(1-\omega_{E X P}\right)}{\phi_{E X P}\left(1+\xi_{E X P} \beta \Gamma^{H}\right)+\left(1-\phi_{E X P}\right) \omega_{E X P}}\left(q_{t}-p_{t}^{E X P}\right) \\
& +\frac{\xi_{E X P}\left(\phi_{E X P}+\left(1-\phi_{E X P}\right) \omega_{E X P}\right)}{\phi_{E X P}\left(1+\xi_{E X P} \beta \Gamma^{H}\right)+\left(1-\phi_{E X P}\right) \omega_{E X P}} \pi_{t-1}^{E X P} \\
& +\frac{\phi_{E X P} \beta \Gamma^{H}}{\phi_{E X P}\left(1+\xi_{E X P} \beta \Gamma^{H}\right)+\left(1-\phi_{E X P}\right) \omega_{E X P}} \mathbb{E}_{t} \pi_{t+1}^{E X P} .
\end{aligned}
$$

Wage Phillips curve:

$$
\begin{aligned}
\pi_{t}^{W}= & \hat{\mu}_{t}^{W}+\frac{\left(1-\phi_{W}\right)\left(1-\phi_{W} \beta \Gamma^{H}\right)\left(1-\omega_{W}\right)}{\phi_{W}\left(1+\xi_{W} \beta \Gamma^{H}\right)+\left(1-\phi_{W}\right) \omega_{W}}\left(m r s_{t}-w_{t}\right) \\
& +\frac{\xi_{W}\left(\phi_{W}+\left(1-\phi_{W}\right) \omega_{W}\right)}{\phi_{W}\left(1+\xi_{W} \beta \Gamma^{H}\right)+\left(1-\phi_{W}\right) \omega_{W}} \pi_{t-1}^{W} \\
& +\frac{\phi_{W} \beta \Gamma^{H}}{\phi_{W}\left(1+\xi_{W} \beta \Gamma^{H}\right)+\left(1-\phi_{W}\right) \omega_{W}} \mathbb{E}_{t} \pi_{t+1}^{W}
\end{aligned}
$$

Marginal rate of substitution:

$$
m r s_{t}=\hat{\varepsilon}_{t}^{L}+\epsilon_{L} l_{t}+\frac{\epsilon_{C}}{1-\psi_{C}}\left(c_{t}^{o}-\psi_{C} c_{t-1}^{o}\right) .
$$

Money demand:

$$
\operatorname{mon}_{t}=-\frac{1}{(R-1) \epsilon_{C}}\left(r_{t}+\hat{\varepsilon}_{t}^{B}\right)+\frac{1}{1-\psi_{C}}\left(c_{t}^{o}-\psi_{C} c_{t-1}^{o}\right) .
$$


Consumption Euler equation:

$$
\begin{aligned}
c_{t}^{o}= & \frac{\psi_{c}}{1+\psi_{c}-\frac{\epsilon_{\beta}\left(1-\psi_{C}\right)}{\epsilon_{C}}} c_{t-1}^{o}+\frac{1}{1+\psi_{c}-\frac{\epsilon_{\beta}\left(1-\psi_{C}\right)}{\epsilon_{C}}} c_{t+1}^{o} \\
- & \frac{1-\psi_{C}}{\left(1+\psi_{C}\right) \epsilon_{C}-\epsilon_{\beta}\left(1-\psi_{C}\right)} \\
& \quad \times \mathbb{E}_{t}\left(r_{t}-\pi_{t+1}^{Z}+\hat{\varepsilon}_{t}^{B}-\gamma_{t+1}^{Z}-\hat{\varepsilon}_{t}^{C}+\hat{\varepsilon}_{t+1}^{C}\right) .
\end{aligned}
$$

Consumption of rule-of-thumb households:

$$
c_{t}^{r o t}=\frac{W L}{C}\left(w_{t}+l_{t}\right) .
$$

Aggregate consumption:

$$
c_{t}=\omega_{o} c_{t}^{o}+\left(1-\omega_{o}\right) c_{t}^{r o t} .
$$

Investment Euler equation:

$$
\begin{aligned}
i_{t}= & \frac{1}{1+\beta \Gamma^{H}}\left(i_{t-1}-\gamma_{t}^{Z}\right)+\frac{\beta \Gamma^{H}}{1+\beta \Gamma^{H}}\left(i_{t+1}+\gamma_{t+1}^{Z}\right) \\
& +\frac{1}{\left(1+\beta \Gamma^{H}\right)\left(\Gamma^{H} \Gamma^{Z} \Gamma^{I}\right)^{2}}\left(\frac{t q_{t}}{\psi_{I}}+\hat{\varepsilon}_{t}^{I}\right) .
\end{aligned}
$$

Tobin's Q:

$$
\begin{aligned}
t q_{t}= & \frac{\left(1-\delta^{K}\right)}{R^{K}+\left(1-\delta^{K}\right)} \mathbb{E}_{t} t q_{t+1}-\left(r_{t}-\mathbb{E}_{t} \pi_{t+1}^{Z}+\hat{\varepsilon}_{t}^{B}\right) \\
& +\frac{R^{K}}{R^{K}+\left(1-\delta^{K}\right)} \mathbb{E}_{t} r_{t+1}^{K} .
\end{aligned}
$$

Capital accumulation equation:

$$
k_{t}=\frac{1-\delta^{K}}{\Gamma^{Z} \Gamma^{I} \Gamma^{H}}\left(k_{t-1}-\gamma_{t}^{Z}\right)+\frac{I}{\Gamma^{H} K}\left(i_{t}+\hat{\varepsilon}_{t}^{I}\right) .
$$

Government spending rule:

$$
g_{t}-g_{t-1}+\gamma_{t}^{Z}=\left(\rho_{G}-1\right) g_{t-1}+\hat{\varepsilon}_{t}^{G} .
$$


Other investment:

$$
i_{t}^{O}-i_{t-1}^{O}+\gamma_{t}^{Z}=\left(\rho_{I^{O}}-1\right) i_{t-1}^{O}+\hat{\varepsilon}_{t}^{I^{O}} .
$$

Export demand:

$$
x_{t}=z_{t}^{F}+\omega_{t}^{F}+\hat{\varepsilon}_{t}^{\kappa^{F}}-\epsilon_{F}\left(p_{t}^{E X P}-p_{t}^{X^{F}}\right) .
$$

Export demand adjustment 42

$$
\omega_{t}^{F}=-\gamma_{t}^{Z}+\left(1-\zeta_{\omega^{F}}\right) \omega_{t-1}^{F} .
$$

Resource constraint:

$$
z_{t}=\frac{C}{Z} c_{t}+\frac{I}{Z} i_{t}+\frac{G}{Z} g_{t}+\frac{I^{O}}{Z} i_{t}^{O}+\frac{X}{Z} x_{t} .
$$

Output gap 43

$$
y_{t}^{g a p}=v_{t}-v_{t}^{\text {flex }} .
$$

Annual CPI inflation 44

$$
\pi_{t}^{Z, a n n}=\pi_{t}^{Z}+\pi_{t-1}^{Z}+\pi_{t-2}^{Z}+\pi_{t-3}^{Z} .
$$

Annual temporary price markup shocks:

$$
\hat{\mu}_{t}^{Z, t e m p, a n n}=\hat{\mu}_{t}^{Z, t e m p}+\hat{\mu}_{t-1}^{Z, t e m p}+\hat{\mu}_{t-2}^{Z, t e m p}+\hat{\mu}_{t-3}^{Z, t e m p} .
$$

Monetary policy rule:

$r_{t}=\theta_{R} r_{t-1}+\left(1-\theta_{R}\right)\left(\theta_{\pi}\left(\pi_{t}^{Z, a n n}-\hat{\mu}_{t}^{Z, t e m p, a n n}\right)+\theta_{Y} y_{t}^{g a p}\right)+\hat{\varepsilon}_{t}^{R}$.

${ }^{42}$ LAP shocks feed into the level of domestic real variables but not into world variables. This adjustment term smooths the effect to ensure that changes in LAP do not cause immediate large changes in export demand.

${ }^{43} v_{t}^{\text {flex }}$ denotes the flexible-price level of GDP - that is, the level of output that would prevail if all prices were (and always had been) flexible and only a subset of shocks affect the economy (which excludes monetary policy and price markup shocks).

${ }^{44}$ Equivalent to final-output inflation given the absence of consumption taxes in the model. 
World VAR (world GDP, world CPI inflation, world interest rate):

$$
\left[\begin{array}{c}
v_{t}^{F} \\
\pi_{t}^{Z^{F}} \\
r_{t}^{F}
\end{array}\right]=P_{1}\left[\begin{array}{c}
v_{t-1}^{F} \\
\pi_{t-1}^{Z^{F}} \\
r_{t-1}^{F}
\end{array}\right]+P_{2}\left[\begin{array}{c}
v_{t-2}^{F} \\
\pi_{t-2}^{Z^{F}} \\
r_{t-2}^{F}
\end{array}\right]+\Sigma\left[\begin{array}{c}
\hat{\varepsilon}_{t}^{f^{D}} \\
\hat{\varepsilon}_{t}^{f^{M}} \\
\hat{\varepsilon}_{t}^{f^{S}}
\end{array}\right]
$$

World trade:

$$
z_{t}^{F}=v_{t}^{F}+\hat{\varepsilon}_{t}^{Z^{F}}
$$

World export price inflation:

$$
\pi_{t}^{X^{F}}=\pi_{t}^{Z^{F}}+p_{t}^{X^{F}}-p_{t-1}^{X^{F}}
$$

UIP condition:

$$
q_{t}=\mathbb{E}_{t} q_{t+1}+r_{t}-r_{t}^{F}-\mathbb{E}_{t}\left(\pi_{t+1}^{Z}-\pi_{t+1}^{Z^{F}}\right)+\hat{\varepsilon}_{t}^{B^{F}} .
$$

Final-output growth:

$$
\gamma_{t}^{Z}=\alpha_{L} \gamma_{t-1}^{Z}+\hat{\varepsilon}_{t}^{L A P}
$$

Price of value-added (relative to final output):

$$
p_{t}^{V}=\pi_{t}^{V}-\pi_{t}^{Z}+p_{t-1}^{V} .
$$

Price of imports (relative to final output):

$$
p_{t}^{M}=\pi_{t}^{M}-\pi_{t}^{Z}+p_{t-1}^{M} .
$$

Price of exports (relative to final output):

$$
p_{t}^{E X P}=\pi_{t}^{E X P}-\pi_{t}^{Z}+p_{t-1}^{E X P} .
$$

Wage (relative to price of final output):

$$
w_{t}=\pi_{t}^{W}-\gamma_{t}^{Z}-\pi_{t}^{Z}+w_{t-1} .
$$




\section{Shock Processes}

Exogenous process for domestic risk premium shock:

$$
\hat{\varepsilon}_{t}^{B}=\rho_{B} \hat{\varepsilon}_{t-1}^{B}+\left(1-\rho_{B}^{2}\right)^{1 / 2} \sigma_{B} \eta_{t}^{B} .
$$

Exogenous process for consumption preference shock:

$$
\hat{\varepsilon}_{t}^{C}=\rho_{C} \hat{\varepsilon}_{t-1}^{C}+\left(1-\rho_{C}^{2}\right)^{1 / 2} \sigma_{C} \eta_{t}^{C} .
$$

Exogenous process for investment-specific shock:

$$
\hat{\varepsilon}_{t}^{I}=\rho_{I} \hat{\varepsilon}_{t-1}^{I}+\left(1-\rho_{I}^{2}\right)^{1 / 2} \sigma_{I} \eta_{t}^{I} .
$$

Exogenous process for other investment shock:

$$
\hat{\varepsilon}_{t}^{I^{O}}=\left(\left(1-\rho_{I^{O}}^{2}\right) /\left(1-\rho_{\eta^{I O}}^{2}\right)\right)^{1 / 2} \sigma_{I^{O}}\left(\eta_{t}^{I^{O}}-\rho_{\eta^{I O}} \eta_{t-1}^{I^{O}}\right) .
$$

Exogenous process for export preference shock:

$$
\hat{\varepsilon}_{t}^{\kappa^{F}}=\rho_{\kappa^{F}} \hat{\varepsilon}_{t-1}^{\kappa^{F}}+\left(1-\rho_{\kappa^{F}}^{2}\right)^{1 / 2} \sigma_{\kappa^{F}} \eta_{t}^{\kappa^{F}} .
$$

Exogenous process for import demand shock:

$$
\hat{\varepsilon}_{t}^{M}=\rho_{M} \hat{\varepsilon}_{t-1}^{M}+\left(1-\rho_{M}^{2}\right)^{1 / 2} \sigma_{M} \eta_{t}^{M} .
$$

Exogenous process for UIP risk premium shock:

$$
\hat{\varepsilon}_{t}^{B^{F}}=\rho_{B^{F}} \hat{\varepsilon}_{t-1}^{B^{F}}+\left(1-\rho_{B^{F}}^{2}\right)^{1 / 2} \sigma_{B^{F}} \eta_{t}^{B^{F}} .
$$

Exogenous process for world trade shock:

$$
\hat{\varepsilon}_{t}^{Z^{F}}=\rho_{Z^{F}} \hat{\varepsilon}_{t-1}^{Z^{F}}+\left(1-\rho_{Z^{F}}^{2}\right)^{1 / 2} \sigma_{Z^{F}} \eta_{t}^{Z^{F}} .
$$

Exogenous process for world export price (relative to world finaloutput price) shock:

$$
p_{t}^{X^{F}}=\rho_{P X^{F}} p_{t-1}^{X^{F}}+\left(1-\rho_{P X^{F}}^{2}\right)^{1 / 2} \sigma_{P X^{F}} \hat{\varepsilon}_{t}^{P X^{F}} .
$$

Exogenous process for the total factor productivity (TFP) shock:

$$
\hat{\varepsilon}_{t}^{T F P}=\rho_{T F P} \hat{\varepsilon}_{t-1}^{T F P}+\left(1-\rho_{T F P}^{2}\right)^{1 / 2} \sigma_{T F P} \eta_{t}^{T F P} .
$$


Exogenous process for LAP shock:

$$
\hat{\varepsilon}_{t}^{L A P}=\rho_{L A P} \hat{\varepsilon}_{t-1}^{L A P}+\left(1-\rho_{L A P}^{2}\right)^{1 / 2} \sigma_{L A P} \eta_{t}^{L A P} .
$$

Exogenous process for labor supply shock:

$$
\hat{\varepsilon}_{t}^{L}=\rho_{L} \hat{\varepsilon}_{t-1}^{L}+\left(1-\rho_{L}^{2}\right)^{1 / 2} \sigma_{L} \eta_{t}^{L} .
$$

Exogenous process for final-output price markup shock:

$$
\hat{\mu}_{t}^{Z}=\rho_{\mu^{z}} \hat{\mu}_{t-1}^{Z}+\left(1-\rho_{\mu^{z}}^{2}\right)^{1 / 2} \sigma_{\mu^{z}} \eta_{t}^{\mu^{Z}} .
$$

Exogenous process for value-added price markup shock:

$$
\hat{\mu}_{t}^{V}=\rho_{\mu^{V}} \hat{\mu}_{t-1}^{V}+\left(1-\rho_{\mu^{V}}^{2}\right)^{1 / 2} \sigma_{\mu^{V}} \eta_{t}^{\mu^{V}} .
$$

Exogenous process for import price markup shock:

$$
\hat{\mu}_{t}^{M}=\rho_{\mu^{M}} \hat{\mu}_{t-1}^{M}+\left(1-\rho_{\mu^{M}}^{2}\right)^{1 / 2} \sigma_{\mu^{M}} \eta_{t}^{\mu^{M}} .
$$

Exogenous process for export price markup shock:

$$
\hat{\mu}_{t}^{X}=\rho_{\mu^{x}} \hat{\mu}_{t-1}^{X}+\left(1-\rho_{\mu^{x}}^{2}\right)^{1 / 2} \sigma_{\mu^{x}} \eta_{t}^{\mu^{X}}
$$

Exogenous process for wage markup shock:

$$
\hat{\mu}_{t}^{W}=\rho_{\mu^{W}} \hat{\mu}_{t-1}^{W}+\left(1-\rho_{\mu^{W}}^{2}\right)^{1 / 2} \sigma_{\mu^{W}} \eta_{t}^{\mu^{W}}
$$

Exogenous process for government spending shock:

$$
\hat{\varepsilon}_{t}^{G}=\left(1-\rho_{G}^{2}\right)^{1 / 2} \sigma_{G} \eta_{t}^{G} .
$$

Exogenous process for monetary policy shock:

$$
\hat{\varepsilon}_{t}^{R}=\left(1-\rho_{R}^{2}\right)^{1 / 2} \sigma_{R} \eta_{t}^{R} .
$$

Exogenous process for temporary final-output price markup shock:

$$
\hat{\mu}_{t}^{Z, t e m p}=\sigma_{t}^{\mu^{Z, t e m p}} \eta_{t}^{\mu^{Z, t e m p}} .
$$




\section{Measurement Equations}

Quarterly real GDP growth45

$$
\operatorname{dlngdpkp} t_{t}=\Delta v_{t}+\gamma_{t}^{Z}+\Gamma_{t}^{Z, t t}+100 \ln \left(\Gamma^{Z} \Gamma^{H}\left(\Gamma^{X}\right)^{-\frac{1-\alpha_{V}}{\alpha_{V}}}\right) .
$$

Quarterly real consumption growth:

$$
\operatorname{dlnckp}_{t}=\Delta c_{t}+\gamma_{t}^{Z}+\Gamma_{t}^{Z, t t}+100 \ln \left(\Gamma^{Z} \Gamma^{H}\right) .
$$

Quarterly real business investment growth:

$$
\text { dlnikkp }{ }_{t}=\Delta i_{t}+\gamma_{t}^{Z}+\Gamma_{t}^{Z, t t}+100 \ln \left(\Gamma^{Z} \Gamma^{H} \Gamma^{I}\right) .
$$

Quarterly real government spending growth:

$$
\text { dlngonskp }_{t}=\Delta g_{t}+\gamma_{t}^{Z}+\Gamma_{t}^{Z, t t}+100 \ln \left(\Gamma^{Z} \Gamma^{H} \Gamma^{G}\right) .
$$

Quarterly real export growth:

$$
\operatorname{dlnxkp} p_{t}=\Delta x_{t}+\gamma_{t}^{Z}+\Gamma_{t}^{Z, t t}+\operatorname{dlnxkp} p_{t}^{t t}+100 \ln \left(\Gamma^{Z} \Gamma^{H} \Gamma^{X}\right) .
$$

Quarterly real import growth:

$$
\operatorname{dlnmkp}_{t}=\Delta m_{t}+\gamma_{t}^{Z}+\Gamma_{t}^{Z, t t}+\operatorname{dlnmkp} p_{t}^{t t}+100 \ln \left(\Gamma^{Z} \Gamma^{H} \Gamma^{X}\right) .
$$

Quarterly hours growth:

$$
\operatorname{dlnhrs}_{t}=\Delta l_{t}+\gamma_{t}^{Z}+100 \ln \left(\Gamma^{H}\right) .
$$

Quarterly Bank Rate:

$$
\operatorname{robs}_{t}=r_{t}+\Pi_{t}^{*, t t}+\Gamma_{t}^{Z, t t}+100 \ln R
$$

Quarterly change in nominal exchange rate:

$$
\text { dlneer }_{t}=\Delta q_{t}-\pi_{t}^{Z}+\pi_{t}^{Z^{F}} \text {. }
$$

\footnotetext{
${ }^{45} \Gamma_{t}^{Z, t t}$ is a deterministic time-varying trend used to incorporate a break in trend productivity growth in the pre- and post-crisis period.
} 
Quarterly CPI inflation:

$$
\text { dlncpisa }_{t}=\pi_{t}^{C}+\Pi_{t}^{*, t t}+100 \ln \Pi^{*} .
$$

Quarterly export price deflator growth:

$$
\operatorname{dlnpxdef}_{t}=\pi_{t}^{E X P}+\Pi_{t}^{*, t t}+\Pi_{t}^{X, t t}+100 \frac{\Pi^{*}}{\Gamma^{X}} .
$$

Quarterly import price deflator growth:

$$
\operatorname{dlnpmdef}_{t}=\pi_{t}^{M}+\Pi_{t}^{*, t t}+\Pi_{t}^{M, t t}+100 \frac{\Pi^{*}}{\Gamma^{X}} .
$$

Quarterly nominal wage growth:

$$
\text { dlnawe }_{t}=\pi_{t}^{W}+\Gamma_{t}^{Z, t t}+\Pi_{t}^{*, t t}+100 \ln \left(\Gamma^{Z} \Pi^{*}\right) .
$$

Quarterly world trade growth:

$$
\operatorname{dlnyf}_{t}=\Delta z_{t}^{F}+\Gamma_{t}^{Z, t t}+\operatorname{dlnyf} f_{t}^{t t}+100 \ln \left(\Gamma^{Z} \Gamma^{H}\right) .
$$

Quarterly world GDP growth:

$\operatorname{dlngdpfkp}{ }_{t}=\Delta v_{t}^{F}+\Gamma_{t}^{Z, t t}+\operatorname{dlngdpfkp} t t+100 \ln \left(\Gamma^{Z} \Gamma^{H}\left(\Gamma^{X}\right)^{-\frac{1-\alpha_{V}}{\alpha_{V}}}\right)$.

Quarterly world CPI inflation:

$$
\operatorname{dlncpif}_{t}=\pi_{t}^{Z^{F}}+\Pi_{t}^{Z F, t t}+\Pi_{t}^{*, F, t t}+100 \ln \Pi^{*} .
$$

Quarterly world export price inflation:

$$
\operatorname{dlnpxfdef} t_{t}=\pi_{t}^{X^{F}}+\Pi_{t}^{X F, t t}+100 \ln \frac{\Pi^{*}}{\Gamma^{X}} .
$$

Quarterly world interest rate:

$$
\operatorname{robsf}_{t}=r_{t}^{F}+\Pi_{t}^{*, F, t t}+\Gamma_{t}^{Z, t t}+\operatorname{robsf}_{t}^{t t}+100 \ln R .
$$




\section{References}

Adolfson, M., S. Laséen, L. Christiano, M. Trabandt, and K. Walentin. 2013. "RAMSES II - Model Description." Technical Report.

Boero, G., J. Smith, and K. F. Wallis. 2008. "Evaluating a ThreeDimensional Panel of Point Forecasts: The Bank of England Survey of External Forecasters." International Journal of Forecasting 24 (3): 354-67.

Bridges, J., and R. Thomas. 2012. "The Impact of QE on the UK Economy-Some Supportive Monetarist Arithmetic." Working Paper No. 442, Bank of England.

British Broadcasting Corporation. 2015. "UK Inflation Rate Turns Negative." May 19.

Burgess, S., E. Fernandez-Corugedo, C. Groth, R. Harrison, F. Monti, K. Theodoridis, and M. Waldron. 2013. "The Bank of England's Forecasting Platform: COMPASS, MAPS, EASE and the Suite of Models." Working Paper No. 471, Bank of England.

Calvo, G. A. 1983. "Staggered Prices in a Utility-Maximizing Framework." Journal of Monetary Economics 12 (3): 383-98.

Christiano, L. J., M. Eichenbaum, and C. L. Evans. 2005. "Nominal Rigidities and the Dynamic Effects of a Shock to Monetary Policy." Journal of Political Economy 113 (1): 1-45.

Christoffel, K., G. Coenen, and A. Warne. 2008. "The New AreaWide Model of the Euro Area: A Micro-founded Open-Economy Model for Forecasting and Policy Analysis." Working Paper No. 0944, European Central Bank.

Chung, H., J. Laforte, D. Reifschneider, and J. C. Williams. 2012. "Have We Underestimated the Likelihood and Severity of Zero Lower Bound Events?" Journal of Money, Credit and Banking 44 (s1): 47-82.

Churm, R., and A. Radia. 2012. "The Funding for Lending Scheme." Quarterly Bulletin (Bank of England) 52 (4): 306-20.

Clarida, R., J. Galí, and M. Gertler. 2002. "A Simple Framework for International Monetary Policy Analysis." Journal of Monetary Economics 49 (5): 879-904.

Coenen, G., and A. Warne. 2014. "Risks to Price Stability, the Zero Lower Bound, and Forward Guidance: A Real-Time Assessment." International Journal of Central Banking 10 (2): 7-54. 
Comin, D., and M. Gertler. 2006. "Medium-Term Business Cycles." American Economic Review 96 (3): 523-51.

Corsetti, G., L. Dedola, and S. Leduc. 2010. "Optimal Monetary Policy in Open Economies." In Handbook of Monetary Economics, Vol. 3, ed. B. M. Friedman and M. Woodford, 861-933 (chapter 16). Elsevier.

Coyle, D. 2015. "A Glimpse into a Future of UK Deflation." Financial Times, April 6. Retrieved from http://www.ft.com.

De Paoli, B. 2009. "Monetary Policy and Welfare in a Small Open Economy." Journal of International Economics 77 (1): 11-22.

Dorich, J., M. Johnston, R. Mendes, S. Murchison, and Y. Zhang. 2013. "ToTEM II: An Updated Version of the Bank of Canada's Quarterly Projection Model." Technical Report No. 100, Bank of Canada.

Economist. 2009. "Now For Something Completely Different." Economist, March 5.

Eggertsson, G. B., and M. Woodford. 2003. "The Zero Bound on Interest Rates and Optimal Monetary Policy." Brookings Papers on Economic Activity 34 (1): 139-235.

Erceg, C. J., D. W. Henderson, and A. T. Levin. 2000. "Optimal Monetary Policy with Staggered Wage and Price Contracts." Journal of Monetary Economics 46 (2): 281-313.

Fawcett, N., L. Koerber, R. Masolo, and M. Waldron. 2015. "Evaluating UK Point and Density Forecasts from an Estimated DSGE Model: The Role of Off-Model Information over the Financial Crisis." Working Paper No. 538, Bank of England.

Fernández-Villaverde, J., G. Gordon, P. Guerrón-Quintana, and J. F. Rubio-Ramírez. 2015. "Nonlinear Adventures at the Zero Lower Bound." Journal of Economic Dynamics and Control 57 (August): 182-204.

Galí, J., and M. Gertler. 1999. "Inflation Dynamics: A Structural Econometric Analysis." Journal of Monetary Economics 44 (2): 195-222.

Galí, J., and T. Monacelli. 2005. "Monetary Policy and Exchange Rate Volatility in a Small Open Economy." Review of Economic Studies 72 (3): 707-34.

Greenslade, J. V., and M. Parker. 2012. "New Insights into PriceSetting Behaviour in the UK: Introduction and Survey Results." Economic Journal 122 (558): F1-F15. 
Guerrieri, L., and M. Iacoviello. 2015. "OccBin: A Toolkit for Solving Dynamic Models with Occasionally Binding Constraints Easily." Journal of Monetary Economics 70 (March): 22-38.

Haberis, A., R. Masolo, and K. Reinold. 2016. "Deflation Probability and the Scope for Monetary Loosening in the United Kingdom." Working Paper No. 627, Bank of England.

Holden, T., and M. Paetz. 2012. "Efficient Simulation of DSGE Models with Inequality Constraints." Discussion Paper No. 1612, School of Economics, University of Surrey.

International Monetary Fund. 2009. "United Kingdom: 2009 Article IV Consultation - Staff Report; Staff Statement; Public Information Notice on the Executive Board Discussion; and Statement by the Executive Director for United Kingdom." IMF Country Report No. 09/212 (July).

—. 2012. "United Kingdom: 2012 Article IV Consultation." IMF Country Report No. 12/190 (July).

- 2016. "United Kingdom: 2015 Article IV ConsultationPress Release; Staff Report; and Statement by the Executive Director for United Kingdom." IMF Country Report No. 16/57 (February).

John, S., M. Roberts, and O. Weeken. 2012. "The Bank of England's Special Liquidity Scheme." Quarterly Bulletin (Bank of England) 52 (1): 57-66.

Khan, M. 2015. "Britain Remains Stuck in Deflation." Telegraph, November 17. Retrieved from http://www.thetelegraph.co.uk.

Kollewe, J. 2015. "UK Economy Poised to Welcome Deflation for First Time Since 1960." Guardian, April 12. Retrieved from http://www.theguardian.com/uk.

Krippner, L. 2013. "Measuring the Stance of Monetary Policy in Zero Lower Bound Environments." Economics Letters 118 (1): 135-38.

Laubach, T., and J. C. Williams. 2016. "Measuring the Natural Rate of Interest Redux." Finance and Economics Discussion Series No. 2016-11, Board of Governors of the Federal Reserve System. Monetary Policy Committee. 2002. "Inflation Report." May, Bank of England.

. 2009. "Minutes of the Monetary Policy Committee Meeting." February, Bank of England. 
- 2011. "Minutes of the Monetary Policy Committee Meeting." October, Bank of England.

- 2012. "Minutes of the Monetary Policy Committee Meeting." November, Bank of England.

_. 2013. "Monetary Policy Trade-offs and Forward Guidance." Bank of England.

- 2014. "Minutes of the Monetary Policy Committee Meeting." February, Bank of England.

- 2015. "Inflation Report." February, Bank of England.

Smets, F., and R. Wouters. 2007. "Shocks and Frictions in US Business Cycles: A Bayesian DSGE Approach." American Economic Review 97 (3): 586-606.

Smith, T. 2012. "Option-Implied Probability Distributions for Future Inflation." Quarterly Bulletin (Bank of England) 52 (3): 224-34.

Steinsson, J. 2003. "Optimal Monetary Policy in an Economy with Inflation Persistence." Journal of Monetary Economics 50 (7): 1425-56.

Swanson, E. T., and J. C. Williams. 2013. "Measuring the Effect of the Zero Lower Bound on Yields and Exchange Rates." Technical Report.

- 2014. "Measuring the Effect of the Zero Lower Bound on Medium- and Longer-Term Interest Rates." American Economic Review 104 (10): 3154-85.

Wu, J. C., and F. D. Xia. 2016. "Measuring the Macroeconomic Impact of Monetary Policy at the Zero Lower Bound." Journal of Money, Credit and Banking 48 (2-3): 253-91. 